\title{
Neuroinflammation and psychiatric illness
}

\author{
Souhel Najjar ${ }^{1,5^{*}}$, Daniel M Pearlman ${ }^{2,5}$, Kenneth Alper ${ }^{4}$, Amanda Najjar ${ }^{3}$ and Orrin Devinsky ${ }^{1,4,5}$
}

\begin{abstract}
Multiple lines of evidence support the pathogenic role of neuroinflammation in psychiatric illness. While systemic autoimmune diseases are well-documented causes of neuropsychiatric disorders, synaptic autoimmune encephalitides with psychotic symptoms often go under-recognized. Parallel to the link between psychiatric symptoms and autoimmunity in autoimmune diseases, neuroimmunological abnormalities occur in classical psychiatric disorders (for example, major depressive, bipolar, schizophrenia, and obsessive-compulsive disorders). Investigations into the pathophysiology of these conditions traditionally stressed dysregulation of the glutamatergic and monoaminergic systems, but the mechanisms causing these neurotransmitter abnormalities remained elusive. We review the link between autoimmunity and neuropsychiatric disorders, and the human and experimental evidence supporting the pathogenic role of neuroinflammation in selected classical psychiatric disorders. Understanding how psychosocial, genetic, immunological and neurotransmitter systems interact can reveal pathogenic clues and help target new preventive and symptomatic therapies.

Keywords: Neuroinflammation, Psychoneuroimmunology, Astrocyte, Microglia, Cytokines, Oxidative stress, Depression, Obsessive-compulsive disorder, Bipolar disorder, Schizophrenia
\end{abstract}

\section{Review} Introduction

As biological abnormalities are increasingly identified among patients with psychiatric disorders, the distinction between neurological and psychiatric illness fades. In addition to systemic autoimmune diseases associated with psychiatric manifestations (for example, lupus) [1], more recently, patients with acute isolated psychosis were identified with synaptic autoimmune encephalitides (Table 1) [2-6]. These patients are often erroneously diagnosed with refractory primary psychotic disorders, delaying initiation of effective immune therapy (Table 1). Additionally, growing evidence supports the pathogenic role of anti-neuronal antibodies in neuropsychiatric disorders [7].

Separation of neurological and psychiatric disorders, supported by Descartes's conception of the 'mind' as an ontologically distinct entity and by the reproducibility of neuropathological abnormalities, dominated medicine in

\footnotetext{
* Correspondence: mna1024231@aol.com

'Department of Neurology, New York University School of Medicine, 550

First Avenue, New York, NY 10016, USA

${ }^{5}$ New York University Comprehensive Epilepsy Center, 550 First Avenue, New York, NY 10016, USA

Full list of author information is available at the end of the article
}

the 19th and early 20th centuries [8]. Since then, an expanding collection of reproducible biological causes, from neurosyphilis, head trauma, stroke, tumor, demyelination and many others caused symptom complexes that overlapped with classic psychiatric disorders [9-11]. More recently, neuroinflammatory and immunological abnormalities have been documented in patients with classical psychiatric disorders.

Peripheral immune modulators can induce psychiatric symptoms in animal models and humans [12-19]. Healthy animals injected with pro-inflammatory IL- $1 \beta$ and tumor necrosis factor alpha (TNF- $\alpha$ ) cytokines demonstrate 'sickness behavior' associated with social withdrawal [12]. In humans, injections of low-dose endotoxin deactivate the ventral striatum, a region critical for reward processing, producing anhedonia a debilitating depressive symptom [14]. Approximately $45 \%$ of non-depressed hepatitis $C$ and cancer patients treated with IFN- $\alpha$ develop depressive symptoms associated with increased serum IL-6 levels $[12,15,17,18]$.

Medical conditions associated with chronic inflammatory and immunological abnormalities, including obesity, diabetes, malignancies, rheumatoid arthritis, and multiple sclerosis, are risk factors for depression and bipolar disorder $[10,12,13,15,17,18]$. The positive 
correlation between these medical conditions and psychiatric illness suggests the presence of a widespread underlying inflammatory process affecting the brain among other organs $[10,19,20]$. A 30-year populationbased study showed that having an autoimmune disease or a prior hospitalization for serious infection increased the risk of developing schizophrenia by $29 \%$ and 60\%, respectively [16]. Further, herpes simplex virus, Toxoplasma gondii, cytomegalovirus, and influenza during pregnancy increase the risk of developing schizophrenia [16].

Peripheral cellular [21,22] (Table 2), and humoral immunological abnormalities [13,21-23] are more prevalent in psychiatric patients relative to healthy controls. In both pilot ( $\mathrm{n}=34$ patients with major depressive disorder (MDD), $\mathrm{n}=43$ healthy controls) and replication studies ( $\mathrm{n}=36 \mathrm{MDD}, \mathrm{n}=43$ healthy controls), a serum assay comprising nine serum biomarkers distinguished MDD subjects from healthy controls with $91.7 \%$ sensitivity and $81.3 \%$ specificity; significantly elevated biomarkers for neuropsychiatric symptoms were the immunological molecules alpha 1 antitrypsin, myeloperoxidase, and soluble TNF- $\alpha$ receptor II [23].

We first review the association between autoimmunity and neuropsychiatric disorders, including: 1) systemic lupus erythematosus (SLE) as a prototype of systemic autoimmune disease; 2) autoimmune encephalitides associated with serum anti-synaptic and glutamic acid decarboxylase (GAD) autoantibodies; and 3) pediatric neuropsychiatric autoimmune disorders associated with streptococcal infections (PANDAS) and pure obsessive-compulsive disorder (OCD) associated with anti-basal ganglia/thalamic autoantibodies. We then discuss the role of innate inflammation/autoimmunity in classical psychiatric disorders, including MDD, bipolar disorder (BPD), schizophrenia, and OCD.

\section{Neuropsychiatric disorders associated with autoimmunity Systemic lupus erythematosus}

Between $25 \%$ to $75 \%$ of SLE patients have central nervous system (CNS) involvement, with psychiatric symptoms typically occurring within the first two years of disease onset. Psychiatric symptoms may include anxiety, mood and psychotic disturbances [97]. Brain magnetic resonance imaging (MRI) is normal in approximately $42 \%$ of neuropsychiatric SLE cases [97]. Microangiopathy and bloodbrain barrier (BBB) breakdown may permit entry of autoantibodies into the brain [97]. These antibodies include anti-ribosomal P (positive in 90\% of psychotic SLE patients) [1], anti-endothelial cell, anti-ganglioside, antidsDNA, anti-2A/2B subunits of N-methyl-D-aspartate receptors (NMDAR) and anti-phospholipid antibodies [97]. Pro-inflammatory cytokines-principally IL-6 [97], S100B
[97], intra-cellular adhesion molecule 1 [97] and matrixmetalloproteinase-9 [98] are also elevated in SLE. Psychiatric manifestations of SLE, Sjögren's disease, Susac's syndrome, CNS vasculitis, CNS Whipple's disease, and Behçet's disease were recently reviewed [1].

\section{Neuropsychiatric autoimmune encephalitides associated with serum anti-synaptic and glutamic acid decarboxylase autoantibodies}

Autoimmune encephalitides are characterized by an acute onset of temporal lobe seizures, psychiatric features, and cognitive deficits [2,3,99-108]. The pathophysiology is typically mediated by autoantibodies targeting synaptic or intracellular autoantigens in association with a paraneo plastic or nonparaneoplastic origin [3]. Anti-synaptic autoantibodies target NR1 subunits of the NMDAR $[100,108,109]$, voltage-gated potassium channel (VGKC) complexes (Kv1 subunit, leucine-rich glioma inactivated (LGI1) and contactin associated protein 2 (CASPR2)) $[101,102,106]$, GluR1 and GluR2 subunits of the amino-3hydroxy-5-methyl-1-4-isoxazolepropionic acid receptor (AMPAR) $[6,110,111]$ and B1 subunits of the $\gamma$-aminobutyric acid $B$ receptors $\left(\mathrm{GABA}_{B} \mathrm{R}\right)[3,99,103]$. Anti-intracellular autoantibodies target onconeuronal and GAD-65 autoantigens $[2,3]$.

The inflammation associated with anti-synaptic autoantibodies, particularly NMDAR-autoantibodies, is typically much milder than that associated with GAD-autoantibodies or anti-neuronal autoantibodies related to systemic autoimmune disorders or paraneoplastic syndromes [2,107].

Although neurological symptoms eventually emerge, psychiatric manifestations, ranging from anxiety $[2,3]$ to psychosis mimicking schizophrenia [2-6], can initially dominate or precede neurological features. Up to twothirds of patients with anti-NMDAR autoimmune encephalitis, initially present to psychiatric services [5]. Anti-synaptic antibodies-mediated autoimmune encephalitides must be considered in the differential of acute psychosis [2-6]. Psychiatric presentations can include normal brain MRI and cerebrospinal fluid (CSF) analysis, without encephalopathy or seizures [2,3,5,6,107]. We reported a case of seropositive GAD autoantibodies associated with biopsy-proven neuroinflammation, despite normal brain MRI and CSF analyses, where the patient presented with isolated psychosis diagnosed as schizophrenia by Diagnostic and Statistical Manual of Mental Disorders, 4th Edition (DSM-IV) criteria [2]. Further, seronegative autoimmune encephalitides can also present with prominent neuropsychiatric disturbances, making diagnosis more elusive [107,112,113]. Psychiatric and neurological features associated with antisynaptic and GAD autoantibodies are summarized in Table 1 [1-6,99-108,114]. 
Serum anti-synaptic and GAD autoantibodies may occur in patients with pure psychiatric disorders $[2,4,5,112,115-121]$. In a prospective cohort of 29 subjects who met the DSM-IV criteria for schizophrenia, serum anti-NMDAR autoantibodies were found in three subjects, and anti-VGKC-complex autoantibodies were found in one subject [5]. Using more sensitive techniques to detect immunoglobulin G (IgG) NR1 autoantibodies in 100 patients with definite schizophrenia, no autoantibodies were identified [122]. However, this study did not assess autoantibodies targeting the NR2 subunit of NMDAR. Other studies reported significantly increased odds of elevated ( $\geq 90$ th percentile non-psychiatric control levels) NR2 antibody levels (odds ratio (OR) 2.78, 95\% confidence interval (CI) 1.26 to $6.14, P=0.012$ ) among individuals with acute mania $(n=43)$, but not in chronic mania or schizophrenia [116].

\section{PANDAS and pure obsessive-compulsive disorder associated with anti-basal ganglia/thalamic autoantibodies}

OCD often complicates neurological disorders involving the basal ganglia including Sydenham's chorea, Huntington's disease and Parkinson's disease. Antibasal ganglia antibodies are implicated in Sydenham's chorea [123]. PANDAS is characterized by acute exacerbations of OCD symptoms and/or motor/phonic tics following a prodromal group A $\beta$-hemolytic streptococcal infection. The pathophysiology is thought to involve cross-reactivity between anti-streptococcal antibodies and basal ganglia proteins [124]. The clinical overlap between the PANDAS and pure OCD suggests a common etiological mechanism [125].

Among a random cohort of 21 pure OCD patients, 91.3\% had CSF anti-basal ganglia $(P<0.05)$ and anti-thalamic autoantibodies $(P<0.005)$ at $43 \mathrm{kDa}[88]$, paralleling functional abnormalities in the cortico-striatal-thalamo-cortico circuitry of OCD subjects [84]. Another study documented that $42 \%(n=21)$ of OCD pediatric and adolescent subjects had serum anti-basal ganglia autoantibodies at 40, 45, and $60 \mathrm{kDa}$ compared to $2 \%$ to $10 \%$ of controls $(P=0.001)$ [7]. Anti-basal ganglia autoantibodies were detected in the sera of $64 \%$ of PANDAS subjects $(n=14)$, compared to only $9 \%$ $(\mathrm{n}=2)$ of streptococcal-positive/OCD-negative controls $(P<0.001)$ [126]. One study found no difference between the prevalence of anti-basal ganglia autoantibodies in OCD $(5.4 \%, \mathrm{n}=4)$ versus MDD controls $(0 \%)$ [127]; however, a limitation was the random use of rat cortex and bovine basal ganglia and cortex that might have limited the identification of seropositive cases.

The basal ganglia autoantigens are aldolase $C(40 \mathrm{kDa})$, neuronal-specific/non-neuronal enolase (45 kDa doublet) and pyruvate kinase M1 (60 kDa)—neuronal glycolytic enzymes-involved in neurotransmission, neuronal metabolism and cell signaling [128]. These enzymes exhibit substantial structural homology to streptococcal proteins [129]. The latest study (96 OCD, 33 MDD, 17 schizophrenia subjects) tested patient serum against pyruvate kinase, aldolase $\mathrm{C}$ and enolase, specifically; a greater proportion of OCD subjects were sero-positive relative to controls $(19.8 \%(\mathrm{n}=19)$ versus $4 \%[\mathrm{n}=2], P=0.012)$ [130].

Yet, in the same study only one of 19 sero-positive OCD subjects also had positive anti-streptolysin $\mathrm{O}$ antibody titers, suggesting that in pure OCD the anti-streptolysin $\mathrm{O}$ antibody seronegativity does not exclude the presence of anti-basal ganglia autoantibodies.

In pure OCD, sero-positivity for anti-basal ganglia/ thalamic antibodies is associated with increased levels of CSF glycine $(P=0.03)$ [88], suggesting that these antibodies contribute to hyperglutamatergia observed in OCD $[84,88,131]$. The improvement of infection-provoked OCD with immune therapies supports the pathogenicity of these autoantibodies [132]. A large NIH trial assessing the efficacy of intravenous immunoglobulin (IVIG) for children with acute onset OCD and anti-streptococcal antibodies is ongoing (ClinicalTrials.gov: NCT01281969). However, the finding of slightly higher CSF glutamate levels in OCD patients with negative CSF anti-basal ganglia/thalamic antibodies as compared to those with positive CSF antibodies suggests that non-immunological mechanisms may play role in OCD [84]. Other mechanisms, including cytokinemediated inflammation (Table 2), are also hypothesized.

\section{Psychiatric disorders associated with innate inflammation}

Disorders of innate inflammation/autoimmunity occur in some patients with classical psychiatric disorders. We discuss innate inflammation-related CNS abnormalitiesincluding glial pathology, elevated cytokines levels, cyclooxygenase activation, glutamate dysregulation, increased S100B levels, increased oxidative stress, and BBB dysfunction-in MDD, BPD, schizophrenia, and OCD. We also describe how innate inflammation may be mechanistically linked to the traditional monoaminergic and glutamatergic abnormalities reported in these disorders (Figures 1 and 2). The therapeutic role of antiinflammatory agents in psychiatric disorders is also reviewed.

\section{Astroglial and oligodendroglial histopathology}

Astroglia and oligodendroglia are essential to neural metabolic homeostasis, behavior and higher cognitive functions [54-56,133-136]. Normal quiescent astroglia provide energy and trophic support to neurons, regulate synaptic neurotransmission (Figure 2), synaptogenesis, cerebral blood flow, and maintain BBB integrity [134,136,137]. Mature oligodendroglia provide energy and trophic support to neurons and maintain $\mathrm{BBB}$ integrity, and regulate axonal repair 
Table 1 Clinical features of anti-synaptic and anti-glutamic acid decarboxylase autoimmune encephalitides

\begin{tabular}{|c|c|c|c|c|c|}
\hline Clinical features & $\begin{array}{l}\text { NMDAR, } \\
\text { (NR1 subunit) }\end{array}$ & $\begin{array}{l}\text { VGKC-complex } \\
\text { (Kv1 subunit, LGI1, CASPR2) }\end{array}$ & $\begin{array}{l}\text { AMPAR } \\
\text { (GluR1, GluR2 } \\
\text { subunits) }\end{array}$ & $\begin{array}{l}\mathrm{GABA}{ }_{B} \mathrm{R} \\
\text { (B1 subunit) }\end{array}$ & GAD (65 kDa) \\
\hline Age (years) & 18 to 50 & Less than 50 & Less than 50 & 60 to 70 & Less than 50 \\
\hline Sex (\% female) & $75 \%$ & $66 \%$ & Greater than 50\% & $50 \%$ & Less than $50 \%$ \\
\hline \multicolumn{6}{|l|}{ Etiology } \\
\hline $\begin{array}{l}\text { Paraneoplastic } \\
\text { (\%, and commonly } \\
\text { occurring cancers) }\end{array}$ & $\begin{array}{l}9 \% \text { to } 56 \% \text { have ovarian teratoma, } \\
\text { predominately females less than } \\
18 \text { years of age }\end{array}$ & $\begin{array}{l}10 \% \text { to } 30 \% \text {; low titers; SCLC; thymoma; } \\
\text { CASPR2 >>LGI-1 }\end{array}$ & $\begin{array}{l}50 \% \text { to } 70 \% ; \mathrm{SCLC} \text {, } \\
\text { breast carcinoma; } \\
\text { thymoma }\end{array}$ & $\begin{array}{l}50 \% \text {; SCLC } \\
\text { thymoma }\end{array}$ & $\begin{array}{l}\text { Rarely associated } \\
\text { with cancer }\end{array}$ \\
\hline Nonparaneoplastic & Approximately 50\% & 70\%; high titers & $30 \%$ to $50 \%$ & $50 \%$ & Frequent \\
\hline \multicolumn{6}{|l|}{$\begin{array}{l}\text { Anatomical } \\
\text { subtype }\end{array}$} \\
\hline $\begin{array}{l}\text { Limbic } \\
\text { encephalitis }\end{array}$ & Less common & Typical & Typical & Typical & Typical \\
\hline Panencephalitis & Typical & Rare (involving basal ganglia) & Unclear & Unclear & Less common \\
\hline CSF abnormal (\%) & $90 \%$ & $40 \%$ & $90 \%$ & $80 \%$ & $20 \%$ \\
\hline $\begin{array}{l}\text { Psychiatric } \\
\text { Features }\end{array}$ & $\begin{array}{l}\text { Common and pronounced: Anxiety, agitation, } \\
\text { paranoid delusions, perceptual changes, erratic } \\
\text { behavior, speech changes, severe psychosis }\end{array}$ & $\begin{array}{l}\text { Agitation, anxiety, panic-attacks, depression, } \\
\text { psychosis, hallucinations, delusions, delirium, } \\
\text { confabulation }\end{array}$ & $\begin{array}{l}\text { Atypical psychosis, } \\
\text { which can be isolated }\end{array}$ & $\begin{array}{l}\text { Paranoia, behavioral } \\
\text { changes }\end{array}$ & $\begin{array}{l}\text { Depression, atypical } \\
\text { psychosis (case reports) }\end{array}$ \\
\hline $\begin{array}{l}\text { Neurological } \\
\text { Features }\end{array}$ & $\begin{array}{l}\text { Early features: seizures, cognitive/memory } \\
\text { impairment; Late features: catatonia, orofacial and } \\
\text { limb dyskinesia, dystonia, autonomic dysfunction, } \\
\text { reduced level of consciousness, aphasia, central } \\
\text { hypoventilation }\end{array}$ & $\begin{array}{l}\text { LGI1: limbic encephalitis (more common): } \\
\text { amnesia temporal lobe seizures, tonic seizures, } \\
\text { and hypernatremia. Extrapyramidal symptoms } \\
\text { (choreoathetosis) and extra-temporal } \\
\text { (faciobrachial dystonic) seizures (less common). } \\
\text { CASPR2: limbic encephalitis, Morvan's syndrome } \\
\text { (neuromyotonia, REM disorder, insomnia, and } \\
\text { autonomic dysfunction). }\end{array}$ & $\begin{array}{l}\text { Memory impairment, } \\
\text { temporal lobe seizures }\end{array}$ & $\begin{array}{l}\text { Prominent temporal lobe } \\
\text { seizures, memory } \\
\text { impairment, concomitant } \\
\text { glutamic acid decarboxylase } \\
\text { autoantibodies }\end{array}$ & $\begin{array}{l}\text { Stiff-person syndrome, } \\
\text { cerebellar ataxia, } \\
\text { cognitive/memory } \\
\text { impairment, epilepsy } \\
\text { (often mesial temporal) }\end{array}$ \\
\hline $\begin{array}{l}\text { Response to } \\
\text { treatment }\end{array}$ & $\begin{array}{l}\text { Highly responsive to immune therapy and } \\
\text { removal of ovarian teratoma }\end{array}$ & Highly responsive to immune therapy & $\begin{array}{l}\text { Moderately responsive } \\
\text { to immune therapy }\end{array}$ & $\begin{array}{l}\text { Moderately responsive } \\
\text { to immune therapy }\end{array}$ & $\begin{array}{l}\text { Often refractory to } \\
\text { immune therapy }\end{array}$ \\
\hline Relapse risk & $\begin{array}{l}20 \% \text { often with psychiatric signs; may indicate } \\
\text { tumor reoccurrence }\end{array}$ & Rarely relapses & $\begin{array}{l}\text { Tendency to relapse } \\
\text { (based on small case } \\
\text { series) }\end{array}$ & $\begin{array}{l}\text { Tendency to relapse (based } \\
\text { on small case series) }\end{array}$ & $\begin{array}{l}\text { Tendency to be chronic } \\
\text { and relapse }\end{array}$ \\
\hline
\end{tabular}

$A M P A R, 2$-amino-3-(5-methyl-3-oxo-1,2-oxazol-4-yl)-propanoic acid receptor; $C A S P R-2$, contactin associated protein 2; $C N S$, central nervous system; $C S F$, cerebrospinal fluid; $G A B A_{B} R$, gamma aminobutyric acid B recepto
$G A D$, glutamic acid decarboxylase; $L G l-1$, leucine-rich glioma inactivated-1; NMDAR, N-methyl-D-aspartate receptor; $R E M$, rapid eye movements; $S C L C$ small cell lung cancer; VGKC; voltage-gated potassium channel. 
and myelination of white matter tracts providing inter- and intra-hemispheric connectivity [54-56]. Both astroglia and oligodendroglia produce antiinflammatory cytokines that can down-regulate harmful inflammation $[52,55]$.

In MDD, astroglial loss is a consistent post-mortem finding in functionally relevant areas, including the anterior cingulate cortex, prefrontal cortex, amygdala, and white matter [35-38,42-46,55,138-147], with few exceptions $[42,43]$. Post-mortem studies revealed reduced glial fibrillary acidic protein (GFAP)-positive astroglial density primarily in the prefrontal cortex $[37,38]$ and amygdala [36]. A large proteomic analysis of frontal cortices from depressed patients showed significant reductions in three GFAP isoforms [39]. Although in one study that reported no significant glial loss, subgroup analysis revealed a significant decrease (75\%) in GFAP-positive astroglial density among study subjects younger than 45 years of age [35]. A morphometric study similarly showed no changes in glial density in late-life MDD brains [148]. We hypothesize that the apparent absence of astroglial loss among older MDD patients may reflect secondary astrogliosis [35] that is associated with older age $[42,50]$ rather than a true negative.

Animal studies are consistent with human studies showing astroglial loss in MDD. Wistar-Kyoto ratsknown to exhibit depressive-like behaviors-revealed reduced astroglial density in the same areas as observed in humans [40]. Administration of the astroglial-toxic agent, L-alpha-aminoadipic acid, induces depressivelike symptoms in rats, suggesting that astroglial loss is pathogenic in MDD [41].

Post-mortem studies of MDD subjects documented reduced oligodendroglial density in the prefrontal cortex and amygdala [54-57,66], which may correlate with brain MRI focal white matter changes occasionally noted in some MDD patients [57]. However, microvascular abnormalities may also contribute to these changes [57].

In BPD, some studies demonstrate significant glial loss $[138,143,149,150]$, while others do not $[37,44-46]$. These inconsistent findings may result from lack of control for: 1) treatment with mood stabilizers, because post-hoc analysis reported by some studies showed significant reduction in glial loss only after controlling for treatment with lithium and valproic acid [46]; 2) familial forms of BPD, as glial loss is particularly prominent among BPD patients with a strong family history [143]; and/or, 3) the predominant state of depression versus mania, as glial loss is frequent in MDD [35-38,42-46,55,138-147]. Whether astroglia or oligodendroglia account for the majority of glial loss is unclear; while proteomic analysis revealed a significant decrease in one astroglial GFAP isoform [39], several other post-mortem studies found either unchanged $[36,37]$ or reduced GFAP-positive astroglial expression in the orbitrofrontal cortex [47], or reduced oligodendroglial density [54-56,58,59].
In schizophrenia, astroglial loss is an inconsistent finding $[48,150]$. While some studies showed no significant astroglial loss [42,50,51], several others found reduced astroglial density $[37,38,43,44,48,49,151]$ and significant reductions in two GFAP isoforms [39]. Inconsistent findings may result from: 1) MDD comorbidity, which is often associated with glial loss; 2) age variation, as older patients have increased GFAP-positive astroglia [35,42,50]; 3) regional [150] and cortical layer variability [48]; 4) treatment with antipsychotic drugs, as experimental studies show both reduced [152] and increased [153] astroglial-density related to chronic antipsychotic treatment [70]; and 5) disease state (for example, suicidal versus non-suicidal behavior) [154]. Post-mortem studies documented oligodendroglial loss $[54,56,60-65,148,155,156]$, particularly in the prefrontal cortex, anterior cingulate cortex, and hippocampus [148]. Ultrastructural examination of the prefrontal region showed abnormally myelinated fibers in both gray and white matter; both age and duration of illness were positively correlated with the white matter abnormalities [157].

In contrast to neurodegenerative disorders that are commonly associated with astroglial proliferation [136], psychiatric disorders are instead associated with either reduced or unchanged astroglial density [138]. The lack of increased glial density in early-onset psychiatric disorders $[44,138]$ may reflect the slower rate of degenerative progression in psychiatric illnesses [138].

We postulate that degenerative changes associated with psychiatric disorders are subtler and not severe enough to provoke astroglial intracellular transcription factors that positively regulate astrogliosis, including signal transducer activator of transcription 3 and nuclear factor kappa B (NF-kB) [136].

While the majority of post-mortem studies focused on the alteration of glial density in MDD, BPD, and schizophrenia, others described alteration of glial cell morphology, with mixed findings. In MDD and BPD, glial size is either increased or unchanged [55]. One study found reduced glial size in BPD and schizophrenia but not in MDD [43]. A post-mortem study of depressed patients who committed suicide found increased astroglial size in the anterior cingulate white matter but not in the cortex [158]. One study in schizophrenic subjects found markedly decreased astroglial size in layer $\mathrm{V}$ of the dorsolateral prefrontal cortex, notwithstanding that astroglial density is double that of controls in the same layer [48]. The mixed results may partially reflect earlier studies of glial alterations in psychiatric illnesses that did not specify astroglia versus oligodendroglia [148].

Glial loss in psychiatric illnesses may contribute to neuroinflammation through several mechanisms, including abnormal cytokine levels (see Cytokine section), dysregulated glutamate metabolism (see Glutamate section), elevated S100B protein (see S100B section), 
and altered BBB function (see Blood brain barrier section), resulting in impaired cognition and behavior $[44,45,54,133,159]$.

\section{Microglial histopathology}

Microglia are the resident immune cells of the CNS. They provide ongoing immune surveillance and regulate developmental synaptic pruning [160,161]. CNS injury transforms ramified resting microglia into activated elongated rod-shaped and macrophage-like phagocytic amoeboid cells that proliferate and migrate towards the site of injury along chemotactic gradients (that is, microglial activation and proliferation (MAP)) [161]. Human microglial cells express NMDARs that may mediate MAP leading to neuronal injury [162].

In MDD, BPD and schizophrenia, the results of postmortem studies investigating the presence of MAP are mixed. Post-mortem studies revealed elevated MAP in only one out of five MDD subjects [67]. In some BPD disorder patients, increased human leukocyte antigen-DR-positive microglia displaying thickened processes were documented in the frontal cortex [69]. In schizophrenia, while some studies reported elevated MAP relative to controls, others showed no difference between groups $[22,67,70]$. In a post-mortem study assessing MAP in MDD and BPD; quinolinic acid-positive microglial cell density was increased in the subgenual anterior cingulate cortex and anterior midcingulate cortex of MDD and BPD patients who committed suicide relative to controls [53]. Post-hoc analysis revealed this increased MAP was solely attributable to MDD and not BPD, since the positive microglial immunostaining in MDD subjects was significantly greater than that in the BPD subgroup in both the subgenual anterior cingulate and midcingulate cortices, and since the microglia density was similar in both BPD and control groups [53]. A study comparing all three disorders (nine MDD, five BPD, fourteen schizophrenia, ten healthy controls) demonstrated no significant difference in microglial density across the four groups [68].

These mixed results may be attributed to variable microglial immunological markers used among different studies [70] and/or the failure to control for disease severity $[22,53,68]$. Notably, three post-mortem studies of MDD and schizophrenic subjects documented a strong positive correlation between MAP and suicidality in the anterior cingulate cortex and mediodorsal thalamus, independent of psychiatric diagnosis $[22,53,68]$. Thus, MAP may be a state rather than a trait marker for MDD and schizophrenia.

In OCD, animal models suggest that dysfunction and reduction of certain microglial phenotypes, such as those expressing the Hoxb8 gene, which encodes homeobox transcription factor, can cause OCD-like behavior [71,72].
Hoxb8 knockout mice exhibit excessive grooming behavior and anxiety in association with reduced microglial density $[71,72]$. This excessive grooming behavior resembles the behavioral characteristics of human OCD. Hoxb8 injection in adult Hoxb8 knockout mice reverses microglial loss and restores normal behavior [71,72]. The role of these specific microglial phenotypes in human OCD is unclear.

Experimental data suggest that MAP comprises distinctive harmful and neuroprotective phenotypes (Figure 2). Harmful microglia do not express major histocompatibility complex II (MHC-II) and, therefore, cannot act as antigen presenting cells (APC) $[163,164]$; they promote deleterious effects $[17,69,165]$ through proinflammatory cytokine production, nitric oxide synthase signaling $[17,166]$, promoting glial and BBB-pericyte/endothelial cyclooxygenase2 (COX-2) expression [167], inducing astroglial S100B secretion (see $S 100 B$ section), and microglial glutamate release [17,136,168,169]. Harmful microglia also secrete prostaglandin E-2 (PGE-2) that promotes proinflammatory cytokines production, which in turn increases PGE-2 levels in a feed-forward cycle [29]. Further, PGE-2 stimulates COX-2 expression, which mediates the conversion of arachidonic acid to PGE-2, setting up another feed-forward cycle [29].

Neuroprotective microglia by contrast can: 1) express MHC-II in vivo and in vitro $[163,166]$ and act as cognate APC (Figure 2) [163,164,166]; 2) facilitate healing and limit neuronal injury by promoting secretion of antiinflammatory cytokines [17], brain-derived neurotrophic factor [17], and insulin-like growth factor-1 [166]; and 3) express excitatory amino acid transporter-2 (EAAT2) that eliminates excess extracellular glutamate $[163,166]$, and promotes neuroprotective $\mathrm{T}$ lymphocytic autoimmunity (Figure 2) $[163,164]$. However, more studies are needed to confirm the contributory role of neuroprotective microglia to neuropsychiatric disorders in humans.

In vitro animal studies suggest that the ratio of harmful versus neuroprotective microglia can be influenced by the net effect of inflammatory counter-regulatory mechanisms $[15,74,164,166]$. These mechanisms include the number of neuroprotective $\mathrm{CD} 4^{+} \mathrm{CD} 25^{+} \mathrm{FOXP} 3^{+} \mathrm{T}$ regulatory cells ((T regs) Figure 1$)[15,74,164,166]$ and brain cytokine levels; low IFN- $\gamma$ levels may promote neuroprotective microglia (Figure 2) [166], whereas high levels can promote the harmful phenotype [166].

\section{The role of cytokines}

Proinflammatory cytokines include IL-1 $\beta$, IL-2, IL-6, TNF- $\alpha$ and IFN- $\gamma$. They are secreted primarily by microglia, Th1 lymphocytes and M1 phenotype monocytes/ macrophages (Figure 1) $[15,170]$. They promote harmful inflammation. Antiinflammatory cytokines include IL-4, IL-5 and IL-10. They are primarily secreted by astroglia, 
Table 2 Summary of neuroinflammatory and immunological abnormalities observed in pure psychiatric disorders

\begin{tabular}{|c|c|c|c|c|}
\hline Abnormalities & Major depression & Bipolar disorder & Schizophrenia & OCD \\
\hline \multicolumn{5}{|l|}{ Genetics } \\
\hline Concordance & $37 \%$ to $38 \%[24]$ & $40 \%$ to $70 \%[25]$ & $40 \%$ to $50 \%[26]$ & $80 \%$ to $87 \%[27]$ \\
\hline GWAS genes & $\begin{array}{l}\text { Tryptophan hydroxylase-1, } \\
\text { BDNF, 5-HTTLPR, PBRM1 [24] }\end{array}$ & $\begin{array}{l}\text { Tryptophan hydroxylase-2, Voltage-gated } \mathrm{Ca}^{2+} \\
\text { channel a1C, PBRM1, D22S278, ANK3 [25] }\end{array}$ & $\begin{array}{l}\mathrm{GABA}_{\mathrm{A}} \mathrm{R} \text { B2 subunit, COMT, Neuregulin-1, } \\
\text { DISC1 [26] HLA (B, C, DRA1, and DRB1; } \\
\text { antigen presentation, autoimmunity) [28] }\end{array}$ & EAAT3 (SLC1A1) [27] \\
\hline Immunologic genes & $\begin{array}{l}\text { Proteasome } \beta 4 \text { subunit (antigen processing) } \\
\text { [21], T-box } 21 \text { ( }(\text { cell differentiation) [21], } \\
\text { IL-1 [29], TNF-.alpha; [29], G-765C (COX-2) } \\
\text { [30], BDNF [24] }\end{array}$ & $\begin{array}{l}\text { BDNF gene [31]; consistent with } \\
\text { decreased serum BDNF levels }\end{array}$ & $\begin{array}{l}\text { S100B [32,33]; consistent with } \\
\text { increased brain and CSF S100B levels }\end{array}$ & TNF-a [34] \\
\hline \multicolumn{5}{|l|}{ Astroglia } \\
\hline Density & $\begin{array}{l}\text { Decreased (highly reproducible) } \\
\text { [35-41]; few exceptions [42,43] }\end{array}$ & Reduced or no change $[37,44-46]$ & $\begin{array}{l}\text { Reduced or no change } \\
{[37-39,47-49][42,50,51]}\end{array}$ & Insufficient data \\
\hline TDO, KYNA & $\ldots$ & KYNA is increased $[52,53]$ & Both are increased $[21,52]$ & $\ldots$ \\
\hline \multicolumn{5}{|l|}{ Oligodendroglia } \\
\hline Density & Decreased [54-58] & Decreased $[54,56-65]$ & Decreased $[54-58,66]$ & Insufficient data \\
\hline \multicolumn{5}{|l|}{ Microglial activation } \\
\hline $\begin{array}{l}\text { Trait and State } \\
\text { markers }\end{array}$ & $\begin{array}{l}\text { Trait: no }[53,67,68] \text {; State (suicidal): } \\
\text { yes }[22,68]\end{array}$ & Mixed data $[53,68,69]$ & $\begin{array}{l}\text { Trait: no [70]; State (suicidal): } \\
\text { yes }[22,68]\end{array}$ & $\begin{array}{l}\text { Insufficient data; yet, Hoxb8 } \\
(-/-) \text { mice exhibit OCD-like } \\
\text { behavior }[71,72]\end{array}$ \\
\hline IDO, KMO & Both are increased [29] & $\ldots$ & Both are decreased [21],[73] & $\ldots$ \\
\hline Quinolinic acid & Increased [53] & $\ldots$ & $\ldots$ & $\ldots$ \\
\hline \multicolumn{5}{|l|}{ Lymphocytes } \\
\hline $\begin{array}{l}\text { T cells, T regs, } \\
\text { B cells }\end{array}$ & $\begin{array}{l}\text { T cells are decreased }[15,74] ; \\
\text { T regs are decreased }[15,74]\end{array}$ & T regs are increased [75] & $\begin{array}{l}\text { T cells are decreased }[76] ; \text { ' } C D 4^{+}: \\
C D 8^{+} \text {ratio' is decreased }[76] ; \\
\text { B cells are increased }[21,76]\end{array}$ & $\begin{array}{l}\text { 'CD4 }{ }^{+}: \mathrm{CD}^{+}{ }^{+} \text {ratio' } \\
\text { is decreased } \\
\text { [77] (normalized } \\
\text { after SRI treatment) }\end{array}$ \\
\hline \multicolumn{5}{|l|}{ EAAT } \\
\hline $\begin{array}{l}\text { EAATs } 1,2 \\
\text { (astroglial) }\end{array}$ & $\begin{array}{l}\text { Both are decreased in the } \\
\text { DLPFC and ACC [78] }\end{array}$ & $\begin{array}{l}\text { EAAT1 is increased, EAAT2 } \\
\text { is decreased in PFC [79] }\end{array}$ & $\begin{array}{l}\text { Both are increased in PFC [79-81], } \\
\text { and thalamus [82] }\end{array}$ & $\ldots$ \\
\hline $\begin{array}{l}\text { EAATs } 3,4 \\
\text { (neuronal) }\end{array}$ & $\begin{array}{l}\text { EAAT4 is decreased in } \\
\text { striatum [83] }\end{array}$ & $\begin{array}{l}\text { Both are decreased in } \\
\text { striatum [79] }\end{array}$ & $\begin{array}{l}\text { EAAT3 is decreased in striatum [83]; } \\
\text { Both are increased in PFC [79-81] } \\
\text { and thalamus [82] }\end{array}$ & $\begin{array}{l}\text { EAAT3 is decreased } \\
\text { in CSTC circuitry } \\
{[77,84]}\end{array}$ \\
\hline \multicolumn{5}{|l|}{ Glutamate, GABA } \\
\hline $\begin{array}{l}\text { Post-mortem } \\
\text { brain tissue }\end{array}$ & $\begin{array}{l}\text { Glutamate and D-serine are } \\
\text { increased in the frontal cortex }[85,86]\end{array}$ & $\begin{array}{l}\text { Glutamate and D-serine are } \\
\text { increased in DLPFC and } \\
\text { hippocampus [86]. Increased } \\
\text { glutamine in ACC/Parietal-OCC [78] }\end{array}$ & $\begin{array}{l}\text { Glutamine synthetase is } \\
\text { increased [87] }\end{array}$ & $\ldots$ \\
\hline CSF, serum & $\begin{array}{l}\text { Glutamate is increased in both; } \\
\text { serum levels normalized after 5-week }\end{array}$ & $\ldots$ & $\ldots$ & $\begin{array}{l}\text { CSF glutamate is increased } \\
\text { [88]; normalized after one }\end{array}$ \\
\hline
\end{tabular}


Table 2 Summary of neuroinflammatory and immunological abnormalities observed in pure psychiatric disorders (Continued)

\begin{tabular}{|c|c|c|c|c|}
\hline & $\begin{array}{l}\text { antidepressant course }[85,86] ; \\
\text { GABA is decreased in both }[85,86]\end{array}$ & & & $\begin{array}{l}\text { dose of ketamine } \\
\text { (NMDAR antagonist) }\end{array}$ \\
\hline${ }^{1} \mathrm{H}$ MRS & $\begin{array}{l}\text { Glutamate is increased [85,89] Decreased } \\
\text { glutamine synthetase, glutamine, and } \\
\text { GABA (ACC, PFC, DMPFC, VMPFC, amygdala, } \\
\text { hippocampi; normalized with ECT and } \\
\text { disease remission) [78] }\end{array}$ & $\begin{array}{l}\text { GLX is increased in medial PFC } \\
\text { (ACC, DLPFC, parietal-OCC, OCC, } \\
\text { insula, hippocampus) [78,79]; } \\
\text { independent of disease state. }\end{array}$ & $\begin{array}{l}\text { Glutamate is decreased in medial } \\
\text { PFC (including ACC); Increased } \\
\text { glutamine synthetase, glutamine, } \\
\text { and 'glutamine:glutamate ratio' } \\
\text { in PFC [90] }\end{array}$ & $\begin{array}{l}\text { GLX is increased in left } \\
\text { caudate and OFC } \\
\text { (normalized after } \\
\text { successful SRI treatment); } \\
\text { GLX is decreased in } \\
\text { ACC [84] }\end{array}$ \\
\hline \multicolumn{5}{|l|}{$\begin{array}{l}\text { Cytokines } \\
\text { (serum) }\end{array}$} \\
\hline Phenotype & Proinflammatory are increased [91] & $\begin{array}{l}\text { Proinflammatory are increased [92]; } \\
\text { IL-1 } 1 \beta, \mathrm{IL}-1 \mathrm{R} \text {, and IL-6 correlate with } \\
\text { post-mortem brain mRNA } \\
\text { expression [69] }\end{array}$ & $\begin{array}{l}\text { Mixed data: antiinflammatory } \\
\text { and/or proinflammatory, are } \\
\text { increased }[52,94,93]\end{array}$ & $\begin{array}{l}\text { Mixed data: TNF-a } \\
\text { is increased or decreased; } \\
\text { IL-6 is increased or no } \\
\text { change; } \mathrm{L}-1 \beta \text { is } \\
\text { decreased [95] }\end{array}$ \\
\hline $\begin{array}{l}\text { Trait and State } \\
\text { markers }\end{array}$ & $\begin{array}{l}\text { Trait markers: TNF-a, IL-6, and sIL-2R } \\
\text { are increased [91]State markers (suicidal): } \\
\text { TNF-a and IL-6 are increased, and IL-2 } \\
\text { is decreased [96]. }\end{array}$ & $\begin{array}{l}\text { Depressive state: IL-6 } \\
\text { Euthymic state: IL-4 } \\
\text { Manic state: IL-2, IL-4, } \\
\text { IL-6 [92] }\end{array}$ & $\begin{array}{l}\text { Trait makers: IFN- } \gamma, \\
\text { TNF-a, IL-12, sIL-2R, IL-1RA, } \\
\text { sIL-2R [93] State markers: IL-1 } \beta \text {, } \\
\text { IL-6, TGF- } \beta \text { [93] }\end{array}$ & $\begin{array}{l}\text { Trait markers: mixed data } \\
\text { LPS-induced: } \\
\text { TNF-a and IL-6 are } \\
\text { decreased [95] }\end{array}$ \\
\hline \multicolumn{5}{|c|}{ 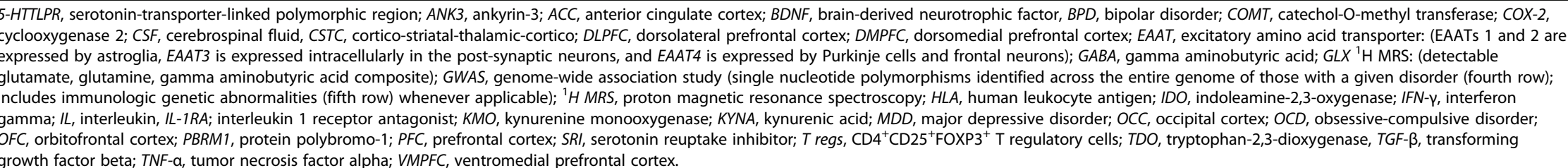 } \\
\hline
\end{tabular}


Th2 lymphocytes, $\mathrm{T}$ regs and M2 phenotype monocytes/ macrophages $[15,52,74]$. They can limit harmful inflammation $[15,74]$ by converting the proinflammatory M1-phenotype into the beneficial antiinflammatory M2-phenotype [15], and potentially by promoting the neuroprotective microglial phenotype $[15,17,74,163,166]$. The role of proinflammatory/antiinflammatory cytokines in psychiatric disorders is supported by several lines of evidence (Figure 1, Table 2) $[15,17,29,52,74]$.

In MDD, the most recent meta-analysis (29 studies, 822 MDD, 726 healthy controls) of serum proinflammatory cytokines confirmed that soluble IL-2 receptor, IL-6 and TNF- $\alpha$ levels are increased in MDD (trait markers) [91], while, IL-1 $\beta$, IL-2, IL-4, IL-8 and IL-10, are not statistically different from controls [91]. In a primary cytokine study comparing MDD subgroups (47 suicidalMDD, 17 non-suicidal MDD, 16 health controls), both sera IL- 6 and TNF- $\alpha$ were significantly higher, while IL-2 levels were significantly lower in MDD subjects who committed suicide relative to both other groups [96]. This finding suggests that IL- 6 and TNF- $\alpha$ are also state markers of MDD [96]. The decrease of serum IL-2 levels associated with acute suicidal behavior may reflect increased binding to its upregulated receptor in the brain; parallel to the aforementioned meta-analysis showing increased soluble IL-2 receptor in MDD [91]. Studies investigating the clinical significance of cytokines in MDD showed that serum cytokine levels are elevated during acute depressive episodes $[171,172]$ and normalized following successful, but not failed, treatment with antidepressants [17] and electroconvulsive therapy [29]; these findings suggest a possible pathogenic role for cytokines.

In $\mathrm{BPD}$, serum cytokine alterations were summarized in a recent review; TNF- $\alpha$, IL- 6 and IL- 8 are elevated during manic and depressive phases, whereas IL-2, IL-4 and IL-6 are elevated during mania [92]. Other studies showed that sera IL-1 $\beta$ and IL-1 receptor levels are not statistically different from healthy controls [92], although tissue studies documented increased levels of IL-1 $\beta$ and IL-1 receptor in the BPD frontal cortex [69].

In schizophrenia, results from studies investigating cytokine abnormalities are conflicting (Table 2). While some studies found both decreased serum proinflammatory (IL-2, IFN- $\gamma$ ) and increased serum and CSF antiinflammatory cytokines (IL-10) [52], others found elevated serum proand antiinflammatory cytokines, with a proinflammatory type dominance $[22,173,174]$. One cytokine meta-analysis (62 studies, 2,298 schizophrenia, 858 healthy controls) showed increased levels of IL-1R antagonist, sIL-2R and IL-6 [174]. However, this study did not account for the use of antipsychotics, which is thought to enhance proinflammatory cytokine production [52]. A more recent cytokine meta-analysis (40 studies, 2,572 schizophrenics,
4,401 controls) that accounted for antipsychotics, found that TNF- $\alpha$, IFN- $\gamma$, IL-12 and sIL-2R are consistently elevated in chronic schizophrenia independent of disease activity (trait markers), while IL-1 $\beta$, IL-6 and transforming growth factor beta positively correlate with disease activity (state markers)[173]. Cell cultures of peripheral blood mononuclear cells (PBMC) obtained from schizophrenic patients produced higher levels of IL- 8 and IL- $1 \beta$ spontaneously as well as after stimulation by LPS, suggesting a role for activated monocytes/macrophages in schizophrenia pathology [175].

In OCD, results from a random survey of sera and CSF cytokines, and LPS-stimulated PBMC studies, are inconsistent [93-95,176-179]. There is a correlation between OCD and a functional polymorphism in the promoter region of the TNF- $\alpha$ gene [34], although low-powered studies did not confirm this association [180]. Therefore, the mixed results from studies documenting either increased or decreased TNF- $\alpha$ cytokine levels $[93,176-178]$ may reflect their variable inclusion of the subset of OCD subjects with this particular polymorphism in their cohorts.

\section{Cytokine response polarization in major depression and schizophrenia}

Cytokine response phenotypes are classified as either proinflammatory Th1 (IL-2, IFN- $\gamma$ ) or antiinflammatory Th2 (IL-4, IL-5, IL-10) according to the immune functions they regulate. While Th1 cytokines regulate cell-mediated immunity directed against intra-cellular antigens, Th2 cytokines regulate humoral immunity directed against extracellular antigens [29,52]. Th1 cytokines are produced by Th1 lymphocytes and M1 monocytes whereas Th2 cytokines are produced by Th2 lymphocytes and M2 monocytes $[29,52]$. In the brain, microglia predominantly secrete Th1 cytokines, whereas astroglia predominately secrete Th2 cytokines [29,52]. The reciprocal ratio of Th1:Th2 cytokines, henceforth 'Th1-Th2 seesaw', is influenced by the proportion of activated microglia (excess Th1) to astroglia (excess Th2) and the interplay between activated $\mathrm{T}$ cells and excessive CNS glutamate levels that we hypothesized to favor Th1 response (Figure 2) $[29,163,166]$.

The Th1-Th2 seesaw imbalance can influence tryptophan metabolism by altering its enzymes [21,52] thereby shifting tryptophan catabolism towards kynurenine (KYN) and KYN catabolism towards either of its two downstream metabolites; microglia quinolinic acid that is Th1 response-mediated or astroglial kynurenic acid (KYNA) (Figure 1) that is Th2 response-mediated [21,29,170].

Tryptophan metabolism enzymes affected by Th1-Th2 seesaw include (Figure 1): indoleamine 2,3-dioxygenase (IDO) expressed by microglia and astroglia, the ratelimiting enzymes that mediate the conversion of tryptophan to KYN and serotonin to 5-hydroxyindoleacetic acid 


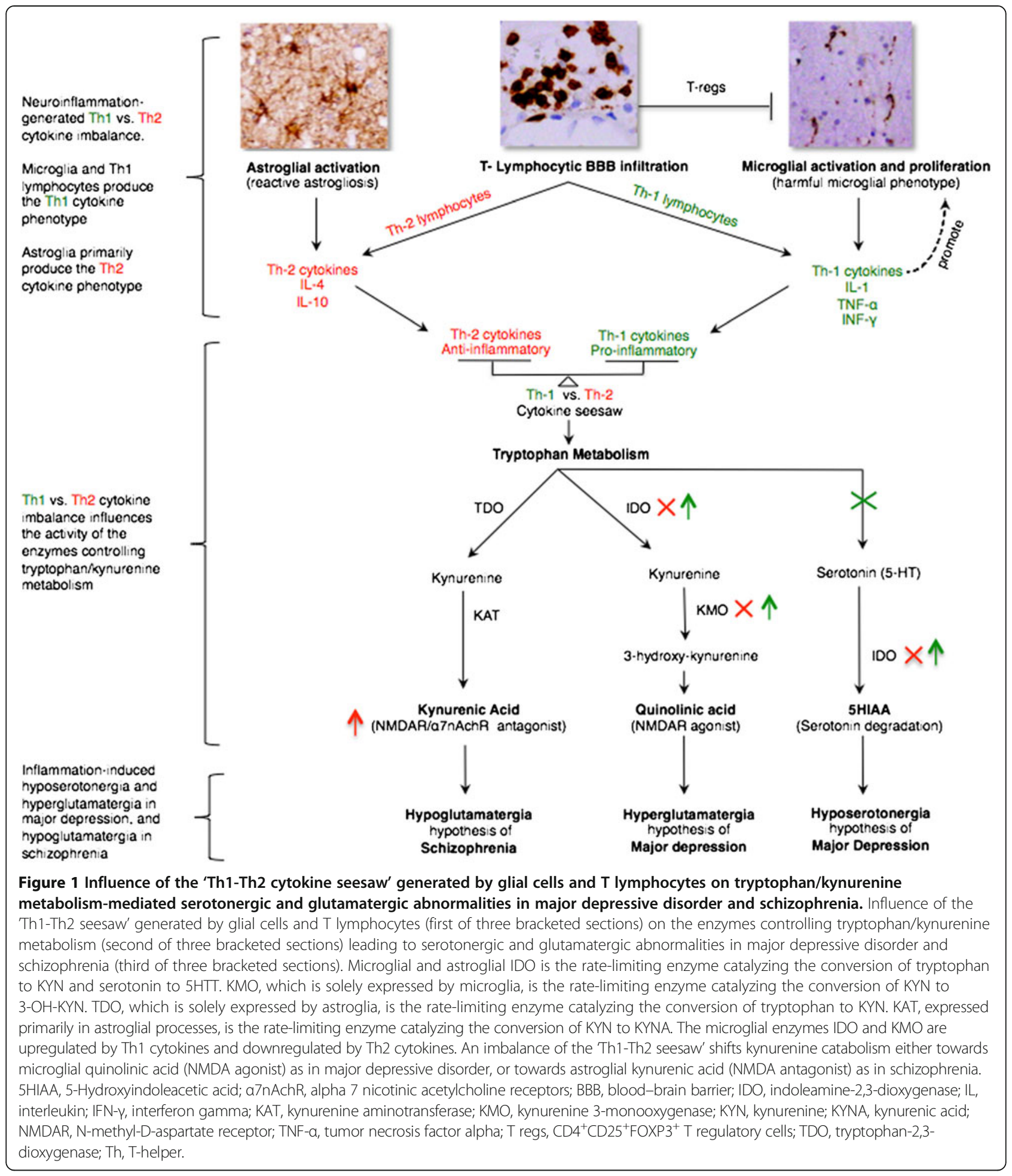

[21,29]. Kynurenine 3-monooxygenase (KMO), solely expressed by microglia, is the rate-limiting enzyme that converts KYN to 3-hydroxykynurenine (3-OH-KYN), which is further metabolized to quinolinic acid [21,29]. Tryptophan-2,3-dioxygenase (TDO), expressed solely by astroglia, is the rate-limiting enzyme that converts tryptophan to KYN [21,29]. Kynurenine aminotransferase (KAT), expressed primarily in astroglial processes, is the rate-limiting enzyme that mediates the conversion of $\mathrm{KYN}$ to KYNA [21,29].

Th1 cytokines activate microglial IDO and KMO, shifting microglial KYN catabolism towards quinolinic 


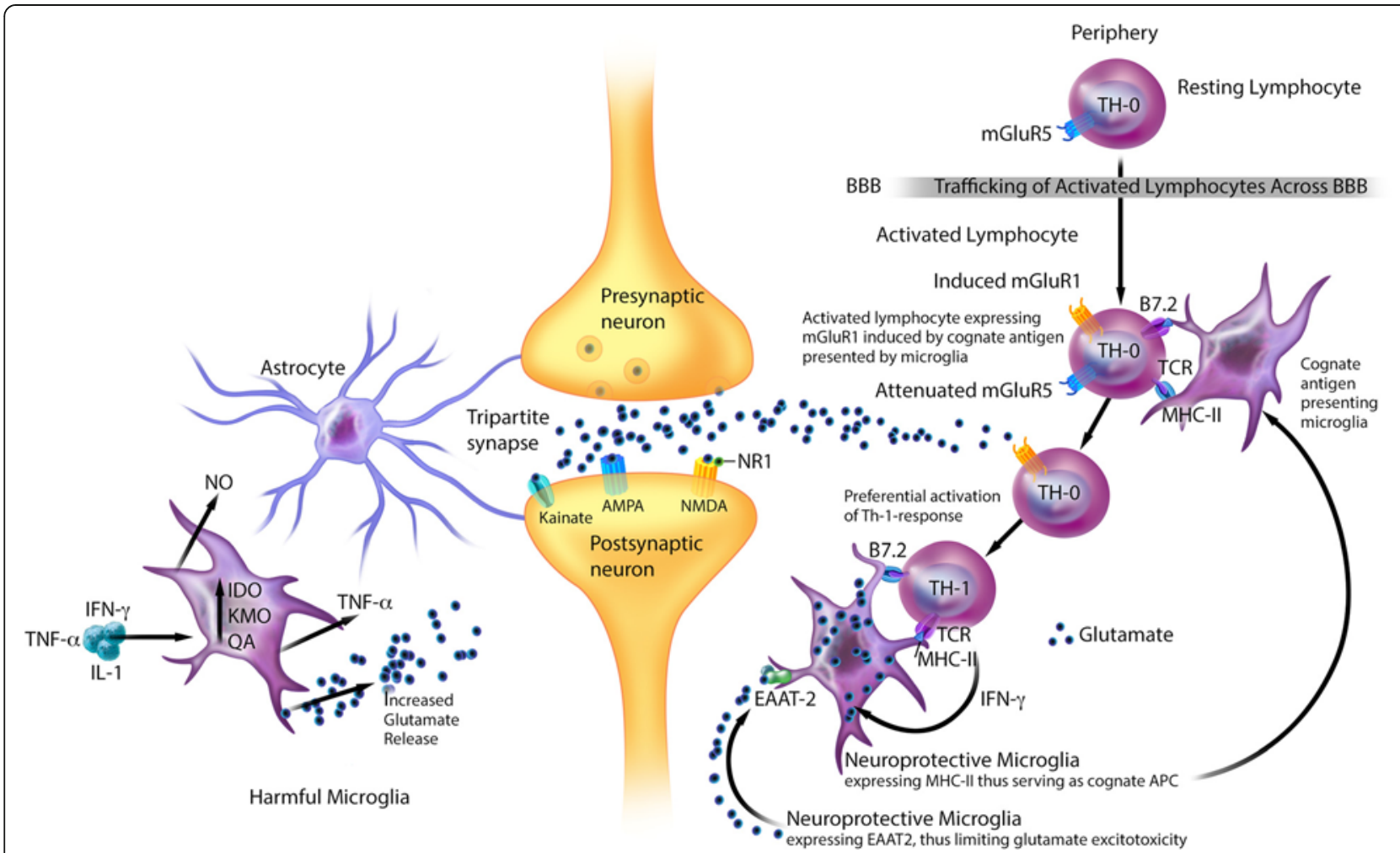

Figure 2 Hypothesis of MDD: excess CNS glutamate may contribute to excess Th1- response promoting neuroprotective microglia. Peripheral resting $T$ lymphocytes constitutively express mGluR5. Activated T lymphocytes, but not resting T lymphocytes, can cross the BBB. In the animal models, the interaction between TCR of activated T lymphocytes and their cognate antigen presenting cells downregulates mGluR5 and induces mGluR1 expressions. Experimental data suggest that excess glutamate can bind to lymphocytic mGluR1 receptors, promoting production of Th1 cytokines. Hypothesis: In some MDD patients, parallel to experimental data, binding of excess CNS glutamate to induced lymphocytic mGluR1 receptors may contribute to an excess Th1 response, including IFN- $\gamma$. We further hypothesize that IFN- $\gamma$ in a small quantity, similar to its in vitro effects on microglia, may induce microglial expression of MHC-II and EAAT-2, allowing microglia to serve as cognate antigen presenting cells and to provide glutamate reuptake function, thereby transforming harmful microglia into neuroprotective phenotype that participate in eliminating excess extracellular glutamate and reducing its excitotoxicity. Therefore, we hypothesize that excess Th1 response in some MDD patients is a double-edged sword; promoting harmful inflammation and serving as a beneficial counter-regulatory mechanism that may limit excess glutamate-related neuroexcitotoxicity? AMPA, 2-amino-3-(5-methyl-3-oxo-1,2-oxazol-4-yl)-propanoic acid; APC, antigen presenting cell; BBB, blood-brain barrier; CNS, central nervous system, EAAT, excitatory amino acid transporter; IDO, indoleamine-2,3-dioxygenase; IFN- $\gamma$, interferon gamma; IL, interleukin; KMO, kynurenine 3-monooxygenase; mGluR1/5, metabotropic glutamate receptors 1 and 5; MHC II, major histocompatibility complex class 2; NMDA, N-methyl-D-aspartate; NO, nitric oxide; NR1, glycine site; QA, quinolinic acid; TCR, T-cell receptor; Th, T-helper; TNF-a, tumor necrosis factor alpha.

acid (NMDAR agonist) synthesis, while Th2 cytokines inactivate microglial IDO and KMO, shifting astroglial KYN catabolism towards TDO- and KAT-mediated KYNA (NMDAR antagonist) synthesis (Figure 1) [21,29].

Th1 and Th2 predominant immunophenotypes have been proposed for MDD and schizophrenia, respectively, based on peripheral, rather than CNS, cytokines patterns $[52,173]$. We believe that peripheral cytokines patterns are unreliable surrogate markers of those in the CNS. Indeed, peripheral cytokine levels can be influenced by many extra-CNS variables, which are not consistently controlled for in several of the peripheral cytokines studies, including: 1) age, body mass index, psychotropic medications, smoking, stress and circadian fluctuations; 2) the influence of disease activity/state on the production of selected cytokines synthesis [95,173]; and 3) the effects of psychotropic agents on cytokines production [52]. The short half-lives and the rapid turnover of serum cytokines [181] (for example, 18 minutes for TNF- $\alpha$ [182] versus 60 minutes for IL-10 [183]), may further limit the reliability of interpreting their levels measured from random sera sampling.

In MDD, there is a consensus that a proinflammatory Th1 immunophenotype response predominates (Table 2) $[17,29]$. High levels of quinolinic acid in post-mortem MDD brains [53], suggest the presence of an upregulated Th1 response (Figure 1) [21,29]. Elevated CNS quinolinic acid can promote calcium influx mediated apoptosis of human astroglia [184], which hypothetically may blunt the 
astroglia-derived Th2 response [29], tipping Th1 versus Th2 seesaw balance in favor of the microglial Th1 response. CNS hyposerotonergia [29] adds further support to an excess Th1 response, which is shown to reduce CNS serotonin synthesis [185] and to increase its degradation (Figure 1) [21,29].

CNS hyperglutamatergia may also contribute to an excess Th1 response in the brain (Figure 2). An in vitro study suggests that the peripheral resting $\mathrm{T}$ lymphocytes constitutively express metabotropic glutamate receptor 5 (mGluR5) [164], whose binding to glutamate inhibits lymphocytic IL-6 release, thereby downregulating autoreactive T-effector cell proliferation [164]. Activated $\mathrm{T}$ lymphocytes, but not resting $\mathrm{T}$ lymphocytes, can cross the BBB [37].

Experimental data suggest that the interaction between $\mathrm{T}$ cell receptors of activated $\mathrm{T}$ lymphocytes and their cognate antigen presenting cells can downregulate mGluR5 and induce mGluR1 expressions [164]. In animal models, binding of excess glutamate to lymphocytic mGluR1 receptors promotes production of Th1 cytokines, including IFN- $\gamma[164]$.

We hypothesize that in some MDD patients, parallel to experimental data [164], the binding of excess CNS glutamate to induced lymphocytic mGluR1 receptors may contribute to an excess Th1 response, including IFN- $\gamma$ (Figure 2). We speculate that IFN- $\gamma$ in a small quantity, similar to its in vitro effects on microglia [166], may induce microglial expression of MHC-II and EAAT2 [163,166], allowing microglia to serve as cognate antigen presenting cells and to provide glutamate reuptake function $[163,164,166]$, thereby transforming harmful microglia into neuroprotective phenotype $[163,166]$ that participate in eliminating excess extracellular glutamate $[163,164,166]$. Therefore, we also hypothesize that excess Th1 response in subgroups of MDD patients is a double-edged sword, promoting harmful inflammation and serving as a beneficial counterregulatory mechanism that may limit excess glutamaterelated neuroexcitotoxicity (Figure 2).

In schizophrenia, while some peripheral cytokine studies suggest the predominance of an antiinflammatory Th2 immunophenotype/response [52], others refute this $[173,174]$. However, we agree with the authors who hypothesized that the Th2 response is the dominant phenotype in schizophrenia [52]. Elevated brain, CSF, and serum levels of KYNA [21,52] suggest downregulation of microglial IDO and KMO, which is a function of Th2 response that shifts astroglial KYN catabolism towards KYNA synthesis (Figure 1) [21,52]. Reduced KMO activity and KMO mRNA expression in post-mortem schizophrenic brains [73] is consistent with excess Th2 response (Figure 1). Increased prevalence of Th2-mediated humoral immunity abnormalities in subgroups of schizophrenia patients-as evidenced by increased B cell counts [21,76], increased production of autoantibodies including antiviral antibodies [76] and increased immunoglobulin E [52]-adds further support to the Th2 response dominance hypothesis.

\section{Neuroinflammation and CNS glutamate dysregulation}

Glutamate mediates cognition and behavior [186]. Synaptic glutamate levels are regulated by high-affinity sodium-dependent glial and neuronal EAATs, namely, the $\mathrm{X}_{\mathrm{AG}^{-}}$system responsible for glutamate reuptake/ aspartate release $[137,164]$ and the sodium-independent astroglial glutamate/cystine antiporter system $\left(\mathrm{X}_{\mathrm{c}^{-}}\right)$responsible for glutamate release/cystine reuptake [164]. Astroglial EAAT1 and EAAT2 provide more than $90 \%$ of glutamate re-uptake [79].

Neuroinflammation can alter glutamate metabolism and the function of its transporters $[15,29,187,188]$, producing cognitive, behavioral, and psychiatric impairments $[15,21,29,79,186,188,189]$. Abnormalities of EAATs function/expression and glutamate metabolism in MDD, BPD, schizophrenia, and OCD are summarized in Table 2.

In MDD, there is evidence for cortical hyperglutamatergia (Table 2). Cortical glutamate levels correlated positively with the severity of depressive symptoms, and a five-week course of antidepressants decreased serum glutamate concentrations [85,86]. A single dose of ketamine, a potent NMDAR antagonist, can reverse refractory MDD for a week $[17,21,29,85]$. Excess CNS glutamate levels can induce neurotoxicity-mediated inflammation $[163,164,188]$, including a proinflammatory Th1 response (Figure 2) [164].

Limited in vitro evidence suggests that inflammation/ proinflammatory cytokines can increase CNS glutamate levels [188] in a feed-forward cycle through several potential mechanisms: 1) proinflammatory cytokines can inhibit $[15,17,168]$ and reverse $[45,137]$ astroglial EAAT-mediated glutamate reuptake function; 2) proinflammatory cytokines can enhance microglial quinolinic acid synthesis [53], which has been experimentally shown to promote synaptosomal glutamate release $[15,17,29,190] ; 3)$ increased COX-2/PGE-2 and TNF- $\alpha$ levels can induce calcium influx [137], which, based on in vitro data, may increase astroglial glutamate and D-serine release [191]; and 4) activated microglia can express excess $\mathrm{X}_{\mathrm{c}^{-}}$antiporter systems that mediate glutamate release $[164,192]$.

In schizophrenia, prefrontal cortical hypoglutamatergia $[87,90,193,194]$ (Table 2) and reduced NMDAR functionality are found [5]. Recent $\mathrm{H}^{1}$ magnetic resonance spectroscopy (MRS) meta-analysis (28 studies, 647 schizophrenia, 608 control) confirmed decreased glutamate and increased glutamine levels in the medial frontal cortex [90]. The contributory role of inflammation to hypoglutamatergia is not proven. Elevated KYNA synthesis in schizophrenia brains [21,52], typically a function of Th2 response (Figure 1), can inhibit NR1 subunit of NMDAR and alpha 7 nicotinic 
acetylcholine receptor ( $\alpha 7 \mathrm{nAchR})$ [195], leading to decreased NMDAR function and reduced $\alpha 7 n A c h R$-mediated glutamate release [195].

In BPD and OCD, data suggest CNS cortical hyperglutamatergia in both disorders (Table 2) [78,84,88,131]. The contribution of inflammation (BPD and OCD) and autoantibodies (OCD) $[7,77,84,88,130]$ to increased CNS glutamate levels requires further investigation.

\section{The role of $\mathrm{S} 100 \mathrm{~B}$}

$\mathrm{S} 100 \mathrm{~B}$ is a $10 \mathrm{kDa}$ calcium-binding protein produced by astroglia, oligodendroglia, and choroid plexus ependymal cells [196]. It mediates its effects on the surrounding neurons and glia via the receptor for advanced glycation end-product [196]. Nanomolar extracellular S100B levels provide beneficial neurotrophic effects, limit stress-related neuronal injury, inhibit microglial TNF- $\alpha$ release, and increase astroglial glutamate reuptake [196]. Micromolar S100B concentrations, predominantly produced by activated astroglia and lymphocytes [196,197], have harmful effects transduced by receptor for advanced glycation end product that include neuronal apoptosis, production of COX-2/PGE-2, IL- $1 \beta$ and inducible nitric oxide species, and upregulation of monocytic/microglial TNF- $\alpha$ secretion $[21,196,198]$.

Serum and, particularly, CSF and brain tissue S100B levels are indicators of glial (predominantly astroglial) activation [199]. In MDD and psychosis, serum S100B levels positively correlate with the severity of suicidality, independent of psychiatric diagnosis [200]. Post-mortem analysis of S100B showed decreased levels in the dorsolateral prefrontal cortex of MDD and BPD, and increased levels in the parietal cortex of BPD [196].

Meta-analysis (193 mood disorder, 132 healthy controls) confirmed elevated serum and CSF S100B levels in mood disorders, particularly during acute depressive episodes and mania [201].

In schizophrenia, brain, CSF and serum S100B levels are elevated [199,202]. Meta-analysis (12 studies, 380 schizophrenia, 358 healthy controls) confirmed elevated serum $\mathrm{S} 100 \mathrm{~B}$ levels in schizophrenia [203]. In post-mortem brains of schizophrenia subjects, S100B-immunoreactive astroglia are found in areas implicated in schizophrenia, including anterior cingulate cortex, dorsolateral prefrontal cortex, orbitofrontal cortex and hippocampi [154]. Elevated S100B levels correlate with paranoid [154] and negativistic psychosis [204], impaired cognition, poor therapeutic response and duration of illness [202]. Genetic polymorphisms in S100B [32] and receptor for advanced glycation end-product genes in schizophrenia cohorts (Table 2) $[32,33,205]$ suggest these abnormalities are likely primary/ pathogenic rather than secondary/biomarkers. Indeed, the decrease in serum S100B levels following treatment with antidepressants [201] and antipsychotics [196] suggests some clinical relevance of S100B to the pathophysiology of psychiatric disorders.

\section{Neuroinflammation and increased oxidative stress}

Oxidative stress is a condition in which an excess of oxidants damages or modifies biological macromolecules such as lipids, proteins and DNA [206-209]. This excess results from increased oxidant production, decreased oxidant elimination, defective antioxidant defenses, or some combination thereof [206-209]. The brain is particularly vulnerable to oxidative stress due to: 1) elevated amounts of peroxidizable polyunsaturated fatty acids; 2) relatively high content of trace minerals that induce lipid peroxidation and oxygen radicals (for example, iron, copper); 3) high oxygen utilization; and 3) limited anti-oxidation mechanisms [206,207].

Excess oxidative stress can occur in MDD [206], BPD [206,207], schizophrenia [207,209], and OCD [206,208]. Peripheral markers of oxidative disturbances include increased lipid peroxidation products (for example, malondialdehyde and 4-hydroxy-2-nonenal), increased nitric oxide (NO) metabolites, decreased antioxidants (for example, glutathione) and altered antioxidant enzyme levels [206,207].

In MDD, increased superoxide radical anion production correlates with increased oxidation-mediated neutrophil apoptosis [206]. Serum levels of antioxidant enzymes (for example, superoxide dismutase-1) are elevated during acute depressive episodes and normalize after selective serotonin reuptake inhibitors (SSRIs) treatment [206]. This suggests that in MDD, serum antioxidant enzyme levels are a state marker, which may reflect a compensatory mechanism that counteracts acute increases in oxidative stress. [206]. In schizophrenia by contrast, CSF soluble superoxide dismutase-1 levels are substantially decreased in early-onset schizophrenic patients relative to chronic schizophrenic patients and healthy controls. This suggests that reduced brain antioxidant enzyme levels may contribute to oxidative damage in acute schizophrenia [210], though larger studies are needed to confirm this finding.

Several additional experimental and human studies examined in more detail the mechanisms underlying the pathophysiology of increased oxidative stress in psychiatric disorders [206-262]. In animal models of depression, brain levels of glutathione are reduced while lipid peroxidation and NO levels are increased [206,262].

Postmortem studies show reduced brain levels of total glutathione in MDD, BPD [206] and schizophrenic subjects [206,207]. Fibroblasts cultured from MDD patients show increased oxidative stress independent of glutathione levels [262], arguing against a primary role of glutathione depletion as the major mechanism of oxidative stress in depression. 
Microglial activation may increase oxidative stress through its production of proinflammatory cytokines and NO [206-209]. Proinflammatory cytokines and high NO levels may promote reactive oxygen species (ROS) formation, which in turn accelerates lipid peroxidation, damaging membrane phospholipids and their membrane-bound monoamine neurotransmitter receptors and depleting endogenous antioxidants. Increased ROS products can enhance microglial activation and increase proinflammatory production via stimulating NF-kB [208], which in turn perpetuates oxidative injury [208], creating the potential for a pathological positive feedback loop in some psychiatric disorders [206-209]. Although neuroinflammation can increase brain glutamate levels $[85,86]$, the role of glutamatergic hyperactivity as a cause of oxidative stress remains unsubstantiated [207].

Mitochondrial dysfunction may contribute to increased oxidative stress in MDD, BPD and schizophrenia [206]. Postmortem studies in these disorders reveal abnormalities in mitochondrial DNA, consistent with the high prevalence of psychiatric disturbances in primary mitochondrial disorders [206]. In vitro animal studies show that proinflammatory cytokines, such as TNF- $\alpha$, can reduce mitochondrial density and impair mitochondrial oxidative metabolism [211,212], leading to increased ROS production [206,213]. These experimental findings may imply mechanistic links among neuroinflammation, mitochondrial dysfunction and oxidative stress [206,213], meriting further investigation of these intersecting pathogenic pathways in human psychiatric disorders.

The vulnerability of neural tissue to oxidative damage varies among different psychiatric disorders based on the neuroanatomical, neurochemical and molecular pathways involved in the specific disorder [207]. Treatment effects may also be critical, as preliminary evidence suggests that antipsychotics, SSRIs and mood stabilizers possess antioxidant properties $[206,207,262]$. The therapeutic role of adjuvant antioxidants (for example, vitamins $C$ and $E$ ) in psychiatric disorder remains to be substantiated by highpowered randomized clinical trials. $\mathrm{N}$-acetylcysteine shows the most promising results to-date, with several randomized placebo-controlled trials demonstrating its efficacy in MDD, BPD and schizophrenia [207].

\section{Blood-brain barrier dysfunction}

The BBB secures the brain's immune-privileged status by restricting the entry of peripheral inflammatory mediators, including cytokines and antibodies that can impair neurotransmission [214,215]. The hypothesis of BBB breakdown and its role in some psychiatric patients $[60,214,216,217]$ is consistent with the increased prevalence of psychiatric comorbidity in diseases associated with its dysfunction, including SLE [97], stroke [11], epilepsy [218] and autoimmune encephalitides (Table 1). An elevated 'CSF:serum albumin ratio' in patients with MDD and schizophrenia suggests increased BBB permeability [214].

In one study (63 psychiatric subjects, 4,100 controls), CSF abnormalities indicative of BBB-damage were detected in $41 \%$ of psychiatric subjects (14 MDD and BPD, 14 schizophrenia), including intrathecal synthesis of IgG, IgM, and/or IgA, mild CSF pleocytosis (5 to 8 cells per $\mathrm{mm}^{3}$ ) and the presence of up to four IgG oligoclonal bands [216]. One post-mortem ultrastructural study in schizophrenia revealed BBB ultrasructural abnormalities in the prefrontal and visual cortices, which included vacuolar degeneration of endothelial cells, astroglial-end-footprocesses, and thickening and irregularity of the basal lamina [60]. However, in this study, the authors did not comment on the potential contribution of postmortem changes to their findings. Another study investigating transcriptomics of BBB endothelial cells in schizophrenic brains identified significant differences among genes influencing immunological function, which were not detected in controls [217].

Oxidation-mediated endothelial dysfunction may contribute to the pathophysiology of BBB dysfunction in psychiatric disorders. Indirect evidence from clinical and experimental studies in depression [219] and, to a lesser extent, in schizophrenia [220] suggests that increased oxidation may contribute to endothelial dysfunction. Endothelial dysfunction may represent a shared mechanism accounting for the known association between depression and cardiovascular disease $[219,221]$, which may be related to decreased levels of vasodilator NO [221-223]. Experimental studies suggest that reduced endothelial NO levels are mechanistically linked to the uncoupling of endothelial nitric oxide synthase (eNOS) from its essential co-factor tetrahydrobiopterin (BH4), shifting its substrate from Larginine to oxygen [224-226]. Uncoupled eNOS promotes synthesis of ROS (for example, superoxide) and reactive nitrogen species (RNS) (for example, peroxynitrite; a product of the interaction of superoxide with NO) [227] rather than NO, leading to oxidation-mediated endothelial dysfunction [224-226].

Animal data showed that SSRIs could restore deficient endothelial NO levels [219], suggesting that anti-oxidative mechanisms may contribute to their antidepressant effects. In humans, L-methylfolate may potentiate antidepressant effects of SSRIs [228], putatively by increasing levels of $\mathrm{BH} 4$, which is an essential cofactor for eNOS recoupling-mediated anti-oxidation [229], as well as for the rate-limiting enzymes of monoamine (that is, serotonin, norepinephrine, dopamine) synthesis [228].

Taken together, both the recent work emphasizing the role of uncoupled eNOS-induced oxidative stress in the pathogenesis of vascular diseases [230,231] and the 
epidemiological studies establishing depression as an independent risk factor for vascular pathologies, such as stroke and heart disease [219,221], add further support to the clinical relevance of uncoupled eNOS-mediated endothelial oxidative damage in depression. Despite abundant evidence for cytokine abnormalities in human psychiatric illnesses and the experimental data showing that proinflammatory cytokines can reduce eNOS expression [212] and increase BBB permeability [215], human evidence that directly links excess proinflammatory cytokines to eNOS dysfunction and/or BBB impairment is lacking.

\section{Imaging and treating inflammation in psychiatric illness Imaging neuroinflammation in situ}

Clinically, neuroinflammation imaging may prove to be crucial for identifying the subgroup of psychiatric patients with neuroinflammation who would be most likely to respond favorably to immunomodulatory therapies. Additionally, such imaging may allow clinicians to monitor neuroinflammation-related disease activity and its response to immune therapy in psychiatric patients. Imaging inflammation in the human brain has traditionally depended upon MRI or CT visualization of extravagated intravenous contrast agents, indicating localized breakdown of the BBB. Gadolinium-enhanced MRI occasionally demonstrates such breakdown in the limbic regions associated with emotional processing in patients with psychiatric disorders attributable to paraneoplastic or other encephalitides $[107,109,113]$. To our knowledge, however, abnormal enhancement has never been demonstrated in any classical psychiatric disorder $[21,214,232]$, despite functional $[214,216]$ and ultrastructural BBB abnormalities [60].

Whether or not subtler neuroinflammation can be visualized in vivo in classical psychiatric disorders remains unknown. One promising technique is positron emission tomography (PET) using radiotracers, such as C11PK11195, which bind to the translocator protein, previously known as the peripheral benzodiazepine receptor, expressed by activated microglia [233,234].

Using this method, patients with schizophrenia were shown to have greater microglial activation throughout the cortex [235] and in the hippocampus during acute psychosis [236]. One study (14 schizophrenia, 14 controls) found no significant difference between [11C] DAA1106 binding in schizophrenia versus controls, but a direct correlation between [11C] DAA1106 binding and the severity of positive symptoms and illness duration in schizophrenia [236].

Investigators from our institution utilized C11-PK11195 PET to demonstrate bi-hippocampal inflammation in a patient with neuropsychiatric dysfunction, including psychotic MDD, epilepsy, and anterograde amnesia, associated with anti-GAD antibodies [237]. However, PK11195 PET has low signal-to-noise properties and requires an on-site cyclotron.

Accordingly, research is being devoted to developing improved translocator protein ligands for PET and SPECT. Future high-powered post-mortem brain tissues studies utilizing protein quantification aimed at elucidating metabolic and inflammatory pathways, CNS cytokines and their binding receptors, in psychiatric disorders are needed to advance our understanding of the autoimmune pathophysiology.

\section{Role of antiinflammatory drugs in psychiatric disorders}

Several human and animal studies suggest that certain antiinflammatory drugs may play an important adjunctive role in the treatment of psychiatric disorders (Table 3). Common drugs are cyclooxygenase inhibitors (Table 3) [238-245], minocycline (Table 3) [240-245], omega-3 fatty acids [246,247], and neurosteroids [248].

Several human studies showed that COX-2 inhibitors could ameliorate psychiatric symptoms of MDD, BPD, schizophrenia and OCD (Table 3) [248]. By contrast, adjunctive treatment with non-selective COX-inhibitors (that is, non-steroidal antiinflammatory drugs (NSAIDs)) may reduce the efficacy of SSRIs [249,250]; two large trials reported that exposure to NSAIDs (but not to either selective COX-2 inhibitors or salicylates) was associated with a significant worsening of depression among a subset of study participants $[249,250]$.

In the first trial, involving 1,258 depressed patients treated with citalopram for 12 weeks, the rate of remission was significantly lower among those who had taken NSAIDs at least once relative to those who had not $(45 \%$ versus $55 \%$, OR $0.64, P=0.0002$ ) [249]. The other trial, involving 1,545 MDD subjects, showed the rate of treatmentresistant depression was significantly higher among those taking NSAIDs (OR 1.55, 95\% CI 1.21 to 2.00) [231]. The worsening of depression in the NSAID groups may not be mechanistically linked to NSAID therapy but instead related to co-existing chronic medical conditions [10,12-18] that necessitate long-term NSAIDs and which are known to be independently associated with increased risk of treatment-resistant depression $[249,251]$. Future studies investigating the impact of NSAIDs on depression and response to antidepressants in humans are needed.

In other experimental studies utilizing acute-stress paradigms to induce a depression-like state in mice, citalopram increased TNF- $\alpha$, IFN- $\gamma$, and p11 (molecular factor linked to depressive behavior in animals) in the frontal cortex, while the NSAID ibuprofen decreased these molecules; NSAIDs also attenuated the antidepressant effects of SSRIs but not other antidepressants [249]. These findings suggest that proinflammatory cytokines may paradoxically exert antidepressant effects despite overwhelming evidence from 
Table 3 Selected studies assessing the efficacy of antiinflammatory agents among patients with unipolar and bipolar depression, schizophrenia, and obsessive-compulsive disorder

\begin{tabular}{|c|c|c|c|c|}
\hline Study & $\begin{array}{l}\text { Study } \\
\text { design }\end{array}$ & Group comparison & $\begin{array}{l}\text { Number } \\
\text { of subjects }\end{array}$ & Functional outcome \\
\hline \multicolumn{5}{|l|}{ COX-2 inhibitors } \\
\hline Müller et al. 2006 [238] & $\mathrm{RCT}$ & $\begin{array}{l}\text { Celecoxib }(200 \mathrm{mg} \text { bid })+ \\
\text { reboxetine versus } \\
\text { placebo + reboxetine }\end{array}$ & 40 MDD (acute) & $\begin{array}{l}\text { Significantly greater decrease in depressive } \\
\text { symptoms in the treatment group }(P=0.035)\end{array}$ \\
\hline $\begin{array}{l}\text { Akhondzadeh et al. } 2009 \\
\text { [239] }\end{array}$ & $\mathrm{RCT}$ & $\begin{array}{l}\text { Celecoxib (200 mg bid) + } \\
\text { fluoxetine versus } \\
\text { placebo + fluoxetine }\end{array}$ & 40 MDD & $\begin{array}{l}\text { Significant improvement of depressive symptoms } \\
(P<0.001) \text {, and a greater percentage of responders } \\
(90 \% \text { versus } 50 \%, P=0.01 \text { ) and remission ( } 35 \% \text { versus } 5 \% \text {, } \\
P=0.04 \text { ) in the treatment group }\end{array}$ \\
\hline $\begin{array}{l}\text { Medlewicz et al. } 2006 \\
\text { [240] }\end{array}$ & $\begin{array}{l}\text { Open- } \\
\text { label }\end{array}$ & $\begin{array}{l}\text { Acetylsalicylic acid } \\
(160 \mathrm{mg} \text { qd) }+ \text { SRI }\end{array}$ & $24 \mathrm{MDD}$ and $\mathrm{BPD}$ & $\begin{array}{l}52.4 \% \text { responder rate, significant improvement } \\
\text { within one week }(P<0.0001) \text { following treatment; } \\
\text { sustained at four weeks }\end{array}$ \\
\hline $\begin{array}{l}\text { ClinicalTrials.gov } \\
\text { NCT00510822 completed, } \\
\text { pending results }\end{array}$ & $\mathrm{RCT}$ & $\begin{array}{l}\text { Cimicoxib ( } 50 \text { mg bid) + } \\
\text { sertraline versus } \\
\text { placebo + sertraline }\end{array}$ & $169 \mathrm{MDD}$ & $\begin{array}{l}\text { Primary outcome measure is mean change in } \\
\text { Hamilton Depression Rating Scale from baseline } \\
\text { to six-week endpoint }\end{array}$ \\
\hline Nery et al. 2008 [263] & $\mathrm{RCT}$ & Celecoxib versus placebo & $\begin{array}{l}28 \text { BPD (depressive } \\
\text { and mixed states) }\end{array}$ & $\begin{array}{l}\text { No significant differences in depressive } \\
\text { or manic symptoms. }\end{array}$ \\
\hline Müller et al. 2002 [242] & $\mathrm{RCT}$ & $\begin{array}{l}\text { Celecoxib }(400 \mathrm{mg} \text { qd })+ \\
\text { risperidone versus } \\
\text { placebo + risperidone }\end{array}$ & $\begin{array}{l}50 \text { (acute } \\
\text { schizophrenia) }\end{array}$ & $\begin{array}{l}\text { Significant improvement of positive and negative } \\
\text { symptoms }(P=0.05) \text {, as well as cognition } \\
(P<0.06) \text { in treatment group at five weeks }\end{array}$ \\
\hline Müller et al. 2010 [244] & $\mathrm{RCT}$ & $\begin{array}{l}\text { Celecoxib }+ \text { amisulpride } \\
\text { versus placebo }+ \\
\text { amisulpride }\end{array}$ & $\begin{array}{l}49 \text { schizophrenia } \\
\text { (first-episode) }\end{array}$ & $\begin{array}{l}\text { Significant improvement of positive and } \\
\text { negative symptoms in celecoxib plus amisulpride } \\
\text { group relative to amisulpride alone ( } P<0.001) \text { at } \\
\text { six-weeks }\end{array}$ \\
\hline Sayyah et al. 2011 [245] & $\mathrm{RCT}$ & $\begin{array}{l}\text { Celecoxib ( } 200 \mathrm{mg} \text { bid })+ \\
\text { fluoxetine versus } \\
\text { placebo + fluoxetine }\end{array}$ & 50 OCD & $\begin{array}{l}\text { Significantly greater reduction in YBOCS scores } \\
\text { in the celecoxib treatment group at two weeks } \\
(P=0.007) \text { and at the eight week end-point }(P=0.037)\end{array}$ \\
\hline \multicolumn{5}{|l|}{ Minocycline } \\
\hline Levine et al. 1996 [264] & $\begin{array}{l}\text { Case } \\
\text { report }\end{array}$ & $\begin{array}{l}\text { Minocycline }(150 \mathrm{mg} \text { qd }) \\
\text { started } 20 \text { years after } \\
\text { disease onset }\end{array}$ & $1 \mathrm{BPD}$ & $\begin{array}{l}\text { Marked decrease in depressive symptoms } \\
\text { (HAM-D score went from } 25 \text { to } 8 \text { ) within } \\
\text { one week following treatment, sustained at } \\
\text { two weeks. }\end{array}$ \\
\hline Levkovitz et al. 2009 [265] & $\mathrm{RCT}$ & $\begin{array}{l}\text { Minocycline ( } 200 \mathrm{mg} \text { qd) } \\
\text { versus placebo }\end{array}$ & $\begin{array}{l}21 \text { schizophrenia } \\
\text { (early and acute- } \\
\text { phase) }\end{array}$ & $\begin{array}{l}\text { Significant improvement of negative symptoms and } \\
\text { cognitive dysfunction in treatment group }(P<0.01)\end{array}$ \\
\hline $\begin{array}{l}\text { ClinicalTrials.gov } \\
\text { NCT01433055 recruiting, } \\
\text { estimated completion } 7 / 15\end{array}$ & RCT & $\begin{array}{l}\text { Minocycline }(100 \mathrm{mg} \text { bid })+ \\
\text { clozapine versus } \\
\text { placebo + clozapine }\end{array}$ & $\begin{array}{l}60 \text { schizophrenia } \\
\text { (refractory to } \geq 2 \\
\text { antipsychotics) }\end{array}$ & $\begin{array}{l}\text { Primary outcome is the improvement in positive } \\
\text { symptoms as measured by the four-item } \\
\text { sub-factor of the Brief Psychiatric Rating Scale. }\end{array}$ \\
\hline Miyaoka et al. 2007 [266] & $\begin{array}{l}\text { Case } \\
\text { series }\end{array}$ & $\begin{array}{l}\text { Minocycline (150 mg qd) + } \\
\text { stable antipsychotic } \\
\text { regiment }\end{array}$ & 2 schizophrenia & $\begin{array}{l}\text { Complete resolution of positive and negative symptoms } \\
\text { with minocycline, sustained for one to two years. } \\
\text { Symptom exacerbation occurred one-week following } \\
\text { minocycline discontinuation (in both cases). In one } \\
\text { patient, the complete resolution of symptoms occurred } \\
\text { at age } 61 \text {, which was } 41 \text { years after disease onset. }\end{array}$ \\
\hline Miyaoka et al. 2008 [267] & $\begin{array}{l}\text { Open- } \\
\text { label }\end{array}$ & Minocycline (150 mg tid) & 22 schizophrenia & $\begin{array}{l}\text { Significant improvement of positive and } \\
\text { negative symptoms at four to eight weeks }(P=0.0001)\end{array}$ \\
\hline Rodriguez et al. 2010 [268] & $\begin{array}{l}\text { Open- } \\
\text { label }\end{array}$ & Minocycline (100 mg bid) & $9 \mathrm{OCD}$ & $\begin{array}{l}22 \% \text { had a } 40 \% \text { to } 46 \% \text { YBOCS reduction at } 12 \text { weeks; the } \\
\text { group as a whole did not have a significant } \\
\text { change in YBOCS score. }\end{array}$ \\
\hline
\end{tabular}

$A S A$, acetylsalicylic acid; $B P D$, bipolar disorder; COX-2, cycloxygenase-2; HAM-D: Hamilton Depression Rating Scale; $M D D$, major depressive disorder; OCD, obsessivecompulsive disorder; SRI, serotonin reuptake inhibitor; $R C T$, randomized controlled trial; YBOCS: Yale-Brown Obsessive-Compulsive Scale.

human studies to the contrary (as reviewed above), which can be attenuated by NSAIDs [249]. At least two considerations may account for this apparent paradox: 1) under some experimental conditions, proinflammatory cytokines have been associated with a neuroprotective role, [251; (for example, IFN- $\gamma$ in low levels can induce neuroprotective microglia (Figure 2) $[163,166,251])$; and 2) whether these responses observed in the context of an acute stress paradigm in an animal model are applicable to endogenous MDD in humans remains unclear [251]. 
The therapeutic effects of COX-2 inhibitors in psychiatric disorders may involve modulation of biosynthesis of COX-2-derived prostaglandins, including proinflammatory PGE2 and antiinflammatory 15-deoxy- $\Delta^{12,14}-\mathrm{PGJ}_{2}$ (15d$\mathrm{PGJ}_{2}$ ) [252,253]. COX-2 inhibitors can reduce PGE2mediated inflammation, which may contribute to the pathophysiology of psychiatric disorders [252,253]. They may also alter the levels $15 \mathrm{~d}-\mathrm{PGJ}_{2}$, and the activity of its nuclear receptor peroxisome proliferator-activated nuclear receptor gamma (PPAR- $\gamma$ ) [252,253].

Several studies suggest that $15 \mathrm{~d}-\mathrm{PGJ}_{2}$ and its nuclear receptor PPAR- $\gamma$ can serve as biological markers for schizophrenia [253]. In schizophrenic patients, serum PGE2 levels are increased, whereas serum levels of $15 \mathrm{~d}-$ $\mathrm{PGJ}_{2}$ are decreased, as is the expression of its nuclear receptor PPAR- $\gamma$ in PBMC [252]. While COX-2 inhibitors may limit the potentially beneficial antiinflammatory effects of the COX-2-dependent ' $15 \mathrm{~d}-\mathrm{PGJ}_{2} / \mathrm{PPAR}-\gamma$ pathway', they may advantageously reduce its harmful effects, including 1) the increased risk for myocardial infarction and certain infections (for example, cytomegalovirus and Toxoplasma gondii) in schizophrenic patients [254] and 2) its pro-apoptotic effects observed in human and animal cancer tissue [255]. Other potential mechanisms of COX-2 inhibitors therapeutic effects may involve their ability to reduce proinflammatory cytokine levels [163], limit quinolinic acid excitotoxicity (as in MDD) and decrease KYNA levels (as in schizophrenia) [128].

Minocycline can be effective in psychiatric disorders (Table 3) [248]. In vitro data suggest that minocycline inhibits MAP, cytokine secretion, 'COX-2/PGE-2 expression', and inducible nitric oxide synthase [256]. Minocycline may also counteract dysregulated glutamatergic and dopaminergic neurotransmission [256].

Omega-3 fatty acid effectiveness in psychiatric disorders is unclear [248]. In a 2011 meta-analysis of 15 randomizedcontrolled trials (916 MDD), omega-3 supplements containing eicosapentaenoic acid $\geq 60 \%$ (dose range 200 to $2,200 \mathrm{mg} / \mathrm{d}$ in excess of the docosahexaenoic acid dose) significantly decreased depressive symptoms as an adjunctive therapy to SRIs $(P<0.001)$ [246]. A subsequent metaanalysis, however, concluded that there is no significant benefit of omega- 3 fatty acids in depression and that the purported efficacy is merely a result of publication bias [247]. A 2012 meta-analysis of 5 randomized-controlled trials including 291 BPD participants found that depressive, but not manic, symptoms were significantly improved among those randomized to omega- 3 fatty acids relative to those taking placebo (Hedges g 0.34, $P=0.025$ ) [257]. In a randomized controlled trial of schizophrenic subjects followed up to 12 months, both positive and negative symptom scores were significantly decreased among the 66 participants randomized to long-chain omega-3 (1.2 g/day for 12 weeks; $P=0.02$ and 0.01 , respectively) [258]; the authors concluded that omega-3 augmentation during the early course of schizophrenia can also prevent relapses and disease progression [258].

A 2012 meta-analysis of seven randomized-controlled trials assessing omega-3 augmentation in 168 schizophrenic patients found no benefit of treatment [259]. The authors of this meta-analysis specifically stated that no conclusion could be drawn regarding the relapse prevention or disease progression endpoints [259]. Experimental data suggest that eicosapentaenoic acid and docosahexaenoic acid mediate their antiinflammatory effects by promoting synthesis of resolvins and protectins, which can inhibit leukocyte infiltration and reduce cytokine production [248].

Neurosteroids, including pregnenolone and its downstream metabolite allopregnanolone, may have a beneficial role in some psychiatric disorders [248,260]. In MDD, several studies found decreased plasma/CSF allopregnanolone levels correlating with symptom severity, which normalized after successful treatment with certain antidepressants (for example, SSRIs), and electroconvulsive therapy [261]. In schizophrenia, brain pregnenolone levels can be altered [248] and serum allopregnanolone levels may increase after some antipsychotic drugs (for example, clozapine and olanzapine) [260]. In three randomized-controlled trials (100 schizophrenia (pooled); treatment duration, approximately nine weeks) positive, negative, and cognitive symptoms, as well as extrapyramidal side effects of antipsychotics were significantly improved in one or more trials among those randomized to pregnenolone relative to those receiving placebo [248]. In one trial, the improvement was sustained with long-term pregnenolone treatment [248]. Pregnenolone can regulate cognition and behavior by potentiating the function of NMDA and $\mathrm{GABA}_{\mathrm{A}}$ receptors [248]. Furthermore, allopregnanolone may exert neuroprotective and antiinflammatory effects [248]. More RCT studies are needed to confirm the beneficial role of neuroactive steroids in early-onset psychiatric disorders in humans.

We are awaiting the results of several ongoing clinical trials investigating the therapeutic effects of other anti-inflammatory agents, including salicylate, an inhibitor of NF-кB (NCT01182727); acetylsalicylic acid (NCT01320982); pravastatin (NCT1082588); and dextromethorphan, a non-competitive NMDAR antagonist that can limit inflammation-induced dopaminergic neuronal injury (NCT01189006).

\section{Future treatment strategies}

Although current immune therapies (for example, IVIG, plasmapheresis, corticosteroids and immunosuppressive agents) are often effective for treating autoimmune encephalitides wherein inflammation is acute, intense and predominately of adaptive origin, their efficacy in classical psychiatric disorders wherein inflammation is chronic, 
much milder, and predominately of innate origin, is limited [2]. Development of novel therapeutics should aim at reversing glial loss [46,138], down-regulating harmful MAP, while optimizing endogenous neuroprotective $T$ regs and beneficial MAP, rather than indiscriminately suppressing inflammation as occurs with current immunosuppressive agents. Additionally, development of potent co-adjuvant antioxidants that would reverse oxidative injury in psychiatric disorders is needed.

\section{Conclusions}

Autoimmunity can cause a host of neuropsychiatric disorders that may initially present with isolated psychiatric symptoms. Innate inflammation/autoimmunity may be relevant to the pathogenesis of psychiatric symptoms in a subset of patients with classical psychiatric disorders. Innate inflammation may be mechanistically linked to the traditional monoaminergic and glutamatergic abnormalities and increased oxidative injury reported in psychiatric illnesses.

\footnotetext{
Abbreviations

3-OH-KYN: 3-hydroxy-kynurenine; a7nAchR: Alpha 7 nicotinic acetylcholine receptors; AMPAR: Amino-3-hydroxy-5-methyl-I-4-isoxazolepropionic acid receptors; APC: Antigen presenting cell; BBB: Blood-brain barrier; BH4: Tetrahydrobiopterin; BPD: Bipolar disorder; Cl: Confidence interval; CNS: Central nervous system; COX-2: Cyclooxegenase-2; CSF: Cerebrospinal fluid; DSM-IV: Diagnostic and Statistical Manual of Mental Disorders 4th Edition; EAATs: Excitatory amino acid transporters; eNOS: Endothelial nitric oxide synthase; GABAB: Gamma aminobutyric acid-beta; GAD: Glutamic acid decarboxylase; GFAP: Glial fibrillary acidic protein; GLX: ${ }^{1} \mathrm{H}$ MRS detectable glutamate, glutamine, gamma aminobutyric acid composite; IDO: Indoleamine 2,3-dioxygenase; Ig: Immunoglobulin; IL: Interleukin; IL-1RA: Interleukin 1 receptor antagonist; IFN- $\gamma$ : Interferon gamma; KAT: Kynurenine aminotransferase; KMO: Kynurenine 3-monooxygenase; KYN: Kynurenine; KYNA: Kynurenic acid; LE: Limbic encephalitis; LPS: Lipopolysaccharide; MAP: Microglial activation and proliferation; MDD: Major depressive disorder; mGluR: Metabotropic glutamate receptor; MHC: II Major histocompatibility complex class two; MRI: Magnetic resonance imaging; MRS: Magnetic resonance spectroscopy; NF-kB: Nuclear factor kappa B; NMDAR: N-methyl-D-aspartate receptor; NR1: Glycine site; OCD: Obsessive-compulsive disorder; OR: Odds ratio; PANDAS: Pediatric neuropsychiatric autoimmune disorders associated with streptococcal infections; PBMC: Peripheral blood mononuclear cells; PET: Positron emission tomography; PFC: Prefrontal cortex; PGE-2: Prostaglandin E2; PPAR$\gamma$ : Peroxisome proliferator-activated nuclear receptor gamma; QA: Quinolinic acid; RNS: Reactive nitrogen species; ROS: Reactive oxygen species; SIL: Soluble interleukin; SLE: Systemic lupus erythematosus; SRI: Serotonin reuptake inhibitor; TNF-a: Tumor necrosis factor alpha; T-regs: $C D 4{ }^{+} \mathrm{CD} 25$ ${ }^{+}{ }^{F O X P 3}{ }^{+}$T regulatory cells; TDO: Tryptophan-2,3-dioxygenase; Th: T-helper; VGKC: Voltage-gated potassium channel; $X_{\mathrm{AG}^{-}}$: Glutamate aspartate transporter; $X_{c}:$ : Sodium-independent astroglial glutamate/cystine antiporter system.
}

\section{Competing interests}

The authors declare that they have no competing interests.

\section{Authors' contributions}

SN and DMP performed an extensive literature review, interpreted data, prepared the manuscript, figures, and tables. KA prepared the section pertaining to oxidative mechanisms and contributed to the manuscript revisions. AN and OD critically-revised and improved the design and quality of the manuscript. All authors read and approved the final manuscript.

\section{Acknowledgments}

We gratefully acknowledge Drs. Josep Dalmau, MD, PhD, Tracy Butler, MD, and David Zazag, MD, PhD, for providing their expertise in autoimmune encephalitides, neuroinflammation imaging, and neuropathology, respectively.

\section{Author details}

${ }^{1}$ Department of Neurology, New York University School of Medicine, 550 First Avenue, New York, NY 10016, USA. ${ }^{2}$ Geisel School of Medicine at Dartmouth, The Dartmouth Institute for Health Policy and Clinical Practice, 30 Lafayette Street, HB 7252, Lebanon, NH 03766, USA. ${ }^{3}$ Department of Pathology, Division of Neuropathology, New York University School of Medicine, 550 First Avenue, New York, NY 10016, USA. ${ }^{4}$ Department of Psychiatry, New York University School of Medicine, New York, NY, USA. ${ }^{5}$ New York University Comprehensive Epilepsy Center, 550 First Avenue, New York, NY 10016, USA

Received: 21 November 2012 Accepted: 28 January 2013 Published: 1 April 2013

\section{References}

1. Kayser MS, Dalmau J: The emerging link between autoimmune disorders and neuropsychiatric disease. J Neuropsychiatry Clin Neurosci 2011, 23:90-97.

2. Najjar S, Pearlman D, Zagzag D, Golfinos J, Devinsky O: Glutamic acid decarboxylase autoantibody syndrome presenting as schizophrenia. Neurologist 2012, 18:88-91.

3. Graus F, Saiz A, Dalmau J: Antibodies and neuronal autoimmune disorders of the CNS. J Neurol 2010, 257:509-517.

4. Lennox BR, Coles AJ, Vincent A: Antibody-mediated encephalitis: a treatable cause of schizophrenia. Br J Psychiatry 2012, 200:92-94.

5. Zandi MS, Irani SR, Lang B, Waters P, Jones PB, McKenna P, Coles AJ, Vincent A, Lennox BR: Disease-relevant autoantibodies in first episode schizophrenia. J Neurol 2011, 258:686-688.

6. Bataller L, Kleopa KA, Wu GF, Rossi JE, Rosenfeld MR, Dalmau J: Autoimmune limbic encephalitis in 39 patients: immunophenotypes and outcomes. J Neurol Neurosurg Psychiatry 2007, 78:381-385.

7. Dale RC, Heyman I, Giovannoni G, Church AW: Incidence of anti-brain antibodies in children with obsessive-compulsive disorder. $\mathrm{Br} J$ Psychiatry 2005, 187:314-319.

8. Kendler KS: The dappled nature of causes of psychiatric illness: replacing the organic-functional/hardware-software dichotomy with empirically based pluralism. Mol Psychiatry 2012, 17:377-388.

9. Keskin G, Sunter G, Midi I, Tuncer N: Neurosyphilis as a cause of cognitive decline and psychiatric symptoms at younger age. J Neuropsychiatry Clin Neurosci 2011, 23:E41-E42.

10. Leboyer M, Soreca I, Scott J, Frye M, Henry C, Tamouza R, Kupfer DJ: Can bipolar disorder be viewed as a multi-system inflammatory disease? J Affect Disord 2012, 141:1-10.

11. Hackett ML, Yapa C, Parag V, Anderson CS: Frequency of depression after stroke: a systematic review of observational studies. Stroke 2005, 36:1330-1340.

12. Dantzer R, O'Connor JC, Freund GG, Johnson RW, Kelley KW: From inflammation to sickness and depression: when the immune system subjugates the brain. Nat Rev Neurosci 2008, 9:46-56.

13. Laske C, Zank M, Klein R, Stransky E, Batra A, Buchkremer G, Schott K: Autoantibody reactivity in serum of patients with major depression, schizophrenia and healthy controls. Psychiatry Res 2008, 158:83-86.

14. Eisenberger NI, Berkman ET, Inagaki TK, Rameson LT, Mashal NM, Irwin MR: Inflammation-induced anhedonia: endotoxin reduces ventral striatum responses to reward. Biol Psychiatry 2010, 68:748-754.

15. Haroon E, Raison CL, Miller AH: Psychoneuroimmunology meets neuropsychopharmacology: translational implications of the impact of inflammation on behavior. Neuropsychopharmacology 2012, 37:137-162.

16. Benros ME, Nielsen PR, Nordentoft M, Eaton WW, Dalton SO, Mortensen PB Autoimmune diseases and severe infections as risk factors for schizophrenia: a 30-year population-based register study. Am J Psychiatry 2011, 168:1303-1310.

17. McNally L, Bhagwagar Z, Hannestad J: Inflammation, glutamate, and glia in depression: a literature review. CNS Spectr 2008, 13:501-510.

18. Harrison NA, Brydon L, Walker C, Gray MA, Steptoe A, Critchley HD: Inflammation causes mood changes through alterations in subgenual cingulate activity and mesolimbic connectivity. Biol Psychiatry 2009, 66:407-414 
19. Raison $\mathrm{CL}$, Miller $\mathrm{AH}$ : Is depression an inflammatory disorder? Curr Psychiatry Rep 2011, 13:467-475.

20. Raison $\mathrm{CL}$, Miller $\mathrm{AH}$ : The evolutionary significance of depression in Pathogen Host Defense (PATHOS-D). Mol Psychiatry 2013, 18:15-37.

21. Steiner J, Bogerts B, Sarnyai Z, Walter M, Gos T, Bernstein HG, Myint AM: Bridging the gap between the immune and glutamate hypotheses of schizophrenia and major depression: Potential role of glial NMDA receptor modulators and impaired blood-brain barrier integrity. World J Biol Psychiatry 2012, 13:482-492.

22. Steiner J, Mawrin C, Ziegeler A, Bielau H, Ullrich O, Bernstein HG, Bogerts $B$ : Distribution of HLA-DR-positive microglia in schizophrenia reflects impaired cerebral lateralization. Acta Neuropathol 2006, 112:305-316.

23. Papakostas Gl, Shelton RC, Kinrys G, Henry ME, Bakow BR, Lipkin SH, Pi B, Thurmond L, Bilello JA: Assessment of a multi-assay, serum-based biological diagnostic test for major depressive disorder: a pilot and replication study. Mol Psychiatry 2013, 18:332-339.

24. Krishnan R: Unipolar depression in adults: epidemiology, pathogenesis, and neurobiology. In UpToDate. Edited by Basow DS. Waltham, MA: UpToDate; 2013.

25. Stovall J: Bipolar disorder in adults: epidemiology and diagnosis. In UpToDate. Edited by Basow DS. UpToDate: Waltham; 2013.

26. Fischer BA, Buchanan RW: Schizophrenia: epidemiology and pathogenesis. In UpToDate. Edited by Basow DS. Waltham, MA: UpToDate; 2013.

27. Nestadt G, Samuels J, Riddle M, Bienvenu OJ 3rd, Liang KY, LaBuda M, Walkup J, Grados M, Hoehn-Saric R: A family study of obsessivecompulsive disorder. Arch Gen Psychiatry 2000, 57:358-363.

28. Stefansson H, Ophoff RA, Steinberg S, Andreassen OA, Cichon S, Rujescu D, Werge T, Pietilainen OP, Mors O, Mortensen PB, Sigurdsson E, Gustafsson O, Nyegaard M, Tuulio-Henriksson A, Ingason A, Hansen T, Suvisaari J, Lonnqvist J, Paunio T, Børglum AD, Hartmann A, Fink-Jensen A, Nordentoft M, Hougaard D, Norgaard-Pedersen B, Böttcher Y, Olesen J, Breuer R, Möller $\mathrm{HJ}$, Giegling I, et al: Common variants conferring risk of schizophrenia. Nature 2009, 460:744-747.

29. Müller N, Schwarz MJ: The immune-mediated alteration of serotonin and glutamate: towards an integrated view of depression. Mol Psychiatry 2007, 12:988-1000

30. Galecki P, Florkowski A, Bienkiewics M, Szemraj J: Functional polymorphism of cyclooxygenase-2 gene (G-765C) in depressive patients. Neuropsychobiology 2010, 62:116-120.

31. Levinson DF: The genetics of depression: a review. Biol Psychiatry 2006, 60:84-92.

32. Zhai J, Cheng L, Dong J, Shen Q, Zhang Q, Chen M, Gao L, Chen X, Wang K, Deng X, Xu Z, Ji F, Liu C, Li J, Dong Q, Chen C: S100B gene polymorphisms predict prefrontal spatial function in both schizophrenia patients and healthy individuals. Schizophr Res 2012, 134:89-94.

33. Zhai J, Zhang Q, Cheng L, Chen M, Wang K, Liu Y, Deng X, Chen X, Shen Q, Xu Z, Ji F, Liu C, Dong Q, Chen C, Li J: Risk variants in the S100B gene, associated with elevated S100B levels, are also associated with visuospatial disability of schizophrenia. Behav Brain Res 2011, 217:363-368.

34. Cappi C, Muniz RK, Sampaio AS, Cordeiro Q, Brentani H, Palacios SA, Marques AH, Vallada H, Miguel EC, Guilherme L, Hounie AG: Association study between functional polymorphisms in the TNF-alpha gene and obsessive-compulsive disorder. Arq Neuropsiquiatr 2012, 70:87-90.

35. Miguel-Hidalgo JJ, Baucom C, Dilley G, Overholser JC, Meltzer HY, Stockmeier CA, Rajkowska G: Glial fibrillary acidic protein immunoreactivity in the prefrontal cortex distinguishes younger from older adults in major depressive disorder. Biol Psychiatry 2000, 48:861-873.

36. Altshuler LL, Abulseoud OA, Foland Ross L, Bartzokis G, Chang S, Mintz J, Hellemann G, Vinters HV: Amygdala astrocyte reduction in subjects with major depressive disorder but not bipolar disorder. Bipolar Disord 2010, 12:541-549.

37. Webster MJ, Knable MB, Johnston-Wilson N, Nagata K, Inagaki M, Yolken RH: Immunohistochemical localization of phosphorylated glial fibrillary acidic protein in the prefrontal cortex and hippocampus from patients with schizophrenia, bipolar disorder, and depression. Brain Behav Immun 2001, 15:388-400

38. Doyle C, Deakin JFW: Fewer astrocytes in frontal cortex in schizophrenia, depression and bipolar disorder. Schizophrenia Res 2002, 53:106.

39. Johnston-Wilson NL, Sims CD, Hofmann JP, Anderson L, Shore AD, Torrey $\mathrm{EF}$, Yolken $\mathrm{RH}$ : Disease-specific alterations in frontal cortex brain proteins in schizophrenia, bipolar disorder, and major depressive disorder, The Stanley Neuropathology Consortium. Mol Psychiatry 2000, 5:142-149.
40. Gosselin RD, Gibney S, O'Malley D, Dinan TG, Cryan JF: Region specific decrease in glial fibrillary acidic protein immunoreactivity in the brain of a rat model of depression. Neuroscience 2009, 159:915-925.

41. Banasr M, Duman RS: Glial loss in the prefrontal cortex is sufficient to induce depressive-like behaviors. Biol Psychiatry 2008, 64:863-870.

42. Cotter D, Hudson L, Landau S: Evidence for orbitofrontal pathology in bipolar disorder and major depression, but not in schizophrenia. Bipolar Disord 2005, 7:358-369.

43. Brauch RA, Adnan El-Masri M, Parker J Jr, El-Mallakh RS: Glial cell number and neuron/glial cell ratios in postmortem brains of bipolar individuals. J Affect Disord 2006, 91:87-90.

44. Cotter DR, Pariante CM, Everall IP: Glial cell abnormalities in major psychiatric disorders: the evidence and implications. Brain Res Bull 2001, 55:585-595.

45. Cotter D, Mackay D, Landau S, Kerwin R, Everall I: Reduced glial cell density and neuronal size in the anterior cingulate cortex in major depressive disorder. Arch Gen Psychiatry 2001, 58:545-553.

46. Bowley MP, Drevets WC, Ongür D, Price JL: Low glial numbers in the amygdala in major depressive disorder. Biol Psychiatry 2002, 52:404-412.

47. Toro CT, Hallak JE, Dunham JS, Deakin JF: Glial fibrillary acidic protein and glutamine synthetase in subregions of prefrontal cortex in schizophrenia and mood disorder. Neurosci Lett 2006, 404:276-281.

48. Rajkowska G, Miguel-Hidalgo JJ, Makkos Z, Meltzer H, Overholser J, Stockmeier C: Layer-specific reductions in GFAP-reactive astroglia in the dorsolateral prefrontal cortex in schizophrenia. Schizophr Res 2002, 57:127-138.

49. Steffek AE, McCullumsmith RE, Haroutunian V, Meador-Woodruff JH: Cortical expression of glial fibrillary acidic protein and glutamine synthetase is decreased in schizophrenia. Schizophr Res 2008, 103:71-82.

50. Damadzic R, Bigelow LB, Krimer LS, Goldenson DA, Saunders RC, Kleinman JE, Herman MM: A quantitative immunohistochemical study of astrocytes in the entorhinal cortex in schizophrenia, bipolar disorder and major depression: absence of significant astrocytosis. Brain Res Bull 2001, 55:611-618.

51. Benes FM, MCSparren J, Bird ED, SanGiovanni JP, Vincent SL: Deficits in small interneurons in prefrontal and cingulate cortices of schizophrenic and schizoaffective patients. Arch Gen Psychiatry 1991, 48:996-1001.

52. Müller N, Schwarz MJ: Immune system and schizophrenia. Curr Immunol Rev 2010, 6:213-220.

53. Steiner J, Walter M, Gos T, Guillemin GJ, Bernstein HG, Sarnyai Z, Mawrin C, Brisch R, Bielau H, Meyer Zu Schwabedissen L, Bogerts B, Myint AM: Severe depression is associated with increased microglial quinolinic acid in subregions of the anterior cingulate gyrus: evidence for an immunemodulated glutamatergic neurotransmission? J Neuroinflammation 2011, 8:94.

54. Vostrikov VM, Uranova NA, Orlovskaya DD: Deficit of perineuronal oligodendrocytes in the prefrontal cortex in schizophrenia and mood disorders. Schizophr Res 2007, 94:273-280.

55. Rajkowska G, Miguel-Hidalgo JJ: Gliogenesis and glial pathology in depression. CNS Neurol Disord Drug Targets 2007, 6:219-233.

56. Uranova NA, Vostrikov VM, Orlovskaya DD, Rachmanova VI: Oligodendroglial density in the prefrontal cortex in schizophrenia and mood disorders: a study from the Stanley Neuropathology Consortium. Schizophr Res 2004, 67:269-275.

57. Uranova N: Damage and loss of oligodendrocytes are crucial in the pathogenesis of schizophrenia and mood disorders (findings form postmortem studies). Neuropsychopharmacology 2004, 29:S33.

58. Uranova NA, Orlovskaya DD, Vostrikov VM, Rachmanova VI: Decreased density of oligodendroglial satellites of pyramidal neurons in layer III in the prefrontal cortex in schizophrenia and mood disorders. Schizophr Res 2002, 53:107.

59. Vostrikov VM, Uranova NA, Rakhmanova VI, Orlovskaia DD: Lowered oligodendroglial cell density in the prefrontal cortex in schizophrenia. Zh Nevrol Psikhiatr Im S S Korsakova 2004, 104:47-51.

60. Uranova NA, Zimina IS, Vikhreva OV, Krukov NO, Rachmanova VI, Orlovskaya DD: Ultrastructural damage of capillaries in the neocortex in schizophrenia. World J Biol Psychiatry 2010, 11:567-578,

61. Hof PR, Haroutunian V, Friedrich VL Jr, Byne W, Buitron C, Perl DP, Davis KL: Loss and altered spatial distribution of oligodendrocytes in the superior frontal gyrus in schizophrenia. Biol Psychiatry 2003, 53:1075-1085.

62. Davis KL, Stewart DG, Friedman Jl, Buchsbaum M, Harvey PD, Hof PR, Buxbaum J, Haroutunian V: White matter changes in schizophrenia: evidence for myelin-related dysfunction. Arch Gen Psychiatry 2003, 60:443-456 
63. Flynn SW, Lang DJ, Mackay AL, Goghari V, Vavasour IM, Whittall KP, Smith GN, Arango V, Mann JJ, Dwork AJ, Falkai P, Honer WG: Abnormalities of myelination in schizophrenia detected in vivo with MRI, and postmortem with analysis of oligodendrocyte proteins. Mol Psychiatry 2003, 8:811-820.

64. Uranova NA, Vostrikov VM, Vikhreva OV, Zimina IS, Kolomeets NS, Orlovskaya DD: The role of oligodendrocyte pathology in schizophrenia. Int J Neuropsychopharmacol 2007, 10:537-545.

65. Byne W, Kidkardnee S, Tatusov A, Yiannoulos G, Buchsbaum MS, Haroutunian V: Schizophrenia-associated reduction of neuronal and oligodendrocyte numbers in the anterior principal thalamic nucleus. Schizophr Res 2006, 85:245-253.

66. Hamidi M, Drevets WC, Price JL: Glial reduction in amygdala in major depressive disorder is due to oligodendrocytes. Biol Psychiatry 2004 55:563-569.

67. Bayer TA, Buslei R, Havas L, Falkai P: Evidence for activation of microglia in patients with psychiatric illnesses. Neurosci Lett 1999, 271:126-128.

68. Steiner J, Bielau H, Brisch R, Danos P, Ullrich O, Mawrin C, Bernstein HG, Bogerts B: Immunological aspects in the neurobiology of suicide: elevated microglial density in schizophrenia and depression is associated with suicide. J Psychiatr Res 2008, 42:151-157.

69. Rao JS, Harry GJ, Rapoport SI, Kim HW: Increased excitotoxicity and neuroinflammatory markers in postmortem frontal cortex from bipolar disorder patients. Mol Psychiatry 2010, 15:384-392.

70. Bernstein HG, Steiner J, Bogerts B: Glial cells in schizophrenia: pathophysiological significance and possible consequences for therapy. Expert Rev Neurother 2009, 9:1059-1071.

71. Chen SK, Trrdik P, Peden E, Cho S, Wu S, Spangrude G, Capecchi MR: Hematopoietic origin of pathological grooming in Hoxb8 mutant mice. Cell 2010, 141:775-785.

72. Antony JM: Grooming and growing with microglia. Sci Signal 2010, 3:jc8.

73. Wonodi I, Stine OC, Sathyasaikumar KV, Roberts RC, Mitchell BD, Hong LE, Kajii Y, Thaker GK, Schwarcz R: Downregulated kynurenine 3monooxygenase gene expression and enzyme activity in schizophrenia and genetic association with schizophrenia endophenotypes. Arch Gen Psychiatry 2011, 68:665-674.

74. Raison CL, Lowry CA, Rook GA: Inflammation, sanitation, and consternation: loss of contact with coevolved, tolerogenic microorganisms and the pathophysiology and treatment of major depression. Arch Gen Psychiatry 2010, 67:1211-1224.

75. Drexhage RC, Hoogenboezem TH, Versnel MA, Berghout A, Nolen WA, Drexhage HA: The activation of monocyte and T cell networks in patients with bipolar disorder. Brain Behav Immun 2011, 25:1206-1213.

76. Steiner J, Jacobs R, Panteli B, Brauner M, Schiltz K, Bahn S, Herberth M, Westphal S, Gos T, Walter M, Bernstein HG, Myint AM, Bogerts B: Acute schizophrenia is accompanied by reduced T cell and increased B cell immunity. Eur Arch Psychiatry Clin Neurosci 2010, 260:509-518.

77. Rotge JY, Aouizerate B, Tignol J, Bioulac B, Burbaud P, Guehl D: The glutamate-based genetic immune hypothesis in obsessive-compulsive disorder, An integrative approach from genes to symptoms. Neuroscience 2010, 165:408-417.

78. Yüksel C, Ongür D: Magnetic resonance spectroscopy studies of glutamate-related abnormalities in mood disorders. Biol Psychiatry 2010, 68:785-794.

79. Rao JS, Kellom M, Reese EA, Rapoport SI, Kim HW: Dysregulated glutamate and dopamine transporters in postmortem frontal cortex from bipolar and schizophrenic patients. J Affect Disord 2012, 136:63-71.

80. Bauer D, Gupta D, Harotunian V, Meador-Woodruff JH, McCullumsmith RE: Abnormal expression of glutamate transporter and transporter interacting molecules in prefrontal cortex in elderly patients with schizophrenia. Schizophr Res 2008, 104:108-120.

81. Matute C, Melone M, Vallejo-Illarramendi A, Conti F: Increased expression of the astrocytic glutamate transporter GLT-1 in the prefrontal cortex of schizophrenics. 2005, 49:451-455.

82. Smith RE, Haroutunian V, Davis KL, Meador-Woodruff $\mathrm{JH}$ : Expression of excitatory amino acid transporter transcripts in the thalamus of subjects with schizophrenia. Am J Psychiatry 2001, 158:1393-1399.

83. McCullumsmith RE, Meador-Woodruff JH: Striatal excitatory amino acid transporter transcript expression in schizophrenia, bipolar disorder, and major depressive disorder. Neuropsychopharmacology 2002, 26:368-375.
84. Pittenger $\mathrm{C}$, Bloch $\mathrm{MH}$, Williams $\mathrm{K}$ : Glutamate abnormalities in obsessive compulsive disorder: neurobiology, pathophysiology, and treatment. Pharmacol Ther 2011, 132:314-332.

85. Hashimoto K: Emerging role of glutamate in the pathophysiology of major depressive disorder. Brain Res Rev 2009, 61:105-123.

86. Hashimoto K, Sawa A, lyo M: Increased levels of glutamate in brains from patients with mood disorders. Biol Psychiatry 2007, 62:1310-1316.

87. Burbaeva G, Boksha IS, Turishcheva MS, Vorobyeva EA, Savushkina OK, Tereshkina EB: Glutamine synthetase and glutamate dehydrogenase in the prefrontal cortex of patients with schizophrenia. Prog Neuropsychopharmacol Biol Psychiatry 2003, 27:675-680.

88. Bhattacharyya S, Khanna S, Chakrabarty K, Mahadevan A, Christopher R, Shankar SK: Anti-brain autoantibodies and altered excitatory neurotransmitters in obsessive-compulsive disorder.

Neuropsychopharmacology 2009, 34:2489-2496.

89. Sanacora G, Gueorguieva R, Epperson CN, Wu YT, Appel M, Rothman DL, Krystal JH, Mason GF: Subtype-specific alterations of gammaaminobutyric acid and glutamate in patients with major depression. Arch Gen Psychiatry 2004, 61:705-713.

90. Marsman A, van den Heuvel MP, Klomp DW, Kahn RS, Luijten PR, Hulshoff Pol HE: Glutamate in schizophrenia: a focused review and meta-analysis of 1H-MRS studies. Schizophr Bull 2013, 39:120-129.

91. Liu Y, Ho RC, Mak A: Interleukin (IL)-6, tumour necrosis factor alpha (TNF-alpha) and soluble interleukin-2 receptors (sIL-2R) are elevated in patients with major depressive disorder: a meta-analysis and metaregression. J Affect Disord 2012, 139:230-239.

92. Brietzke E, Stabellini R, Grassis-Oliveira R, Lafer B: Cytokines in bipolar disorder: recent findings, deleterious effects but promise for future therapeutics. CNS Spectr 2011. http://www.cnsspectrums.com/aspx/ articledetail.aspx?articleid=3596.

93. Denys D, Fluitman S, Kavelaars A, Heijnen C, Westenberg H: Decreased TNF-alpha and NK activity in obsessive-compulsive disorder. Psychoneuroendocrinology 2004, 29:945-952.

94. Brambilla F, Perna G, Bellodi L, Arancio C, Bertani A, Perini G, Carraro C, Gava F: Plasma interleukin-1 beta and tumor necrosis factor concentrations in obsessive-compulsive disorders. Biol Psychiatry 1997, 42:976-981.

95. Fluitman S, Denys D, Vulink N, Schutters S, Heijnen C, Westenberg H: Lipopolysaccharide-induced cytokine production in obsessivecompulsive disorder and generalized social anxiety disorder. Psychiatry Res 2010, 178:313-316.

96. Janelidze S, Mattei D, Westrin A, Traskman-Bendz L, Brundin L: Cytokine levels in the blood may distinguish suicide attempters from depressed patients. Brain Behav Immun 2011, 25:335-339.

97. Postal M, Costallat LT, Appenzeller S: Neuropsychiatric manifestations in systemic lupus erythematosus: epidemiology, pathophysiology and management. CNS Drugs 2011, 25:721-736.

98. Kozora E, Hanly JG, Lapteva L, Filley CM: Cognitive dysfunction in systemic lupus erythematosus: past, present, and future. Arthritis Rheum 2008, 58:3286-3298.

99. Lancaster E, Martinez-Hernandez E, Dalmau J: Encephalitis and antibodies to synaptic and neuronal cell surface proteins. Neurology 2011, 77:179-189.

100. Dalmau J, Lancaster E, Martinez-Hernandez E, Rosenfeld MR, Balice-Gordon R: Clinical experience and laboratory investigations in patients with antiNMDAR encephalitis. Lancet Neurol 2011, 10:63-74.

101. Lai M, Huijbers MG, Lancaster E, Graus F, Bataller L, Balice-Gordon R, Cowell JK, Dalmau J: Investigation of LGI1 as the antigen in limbic encephalitis previously attributed to potassium channels: a case series. Lancet Neurol 2010, 9:776-785.

102. Lancaster E, Huijbers MG, Bar V, Boronat A, Wong A, Martinez-Hernandez E, Wilson C, Jacobs D, Lai M, Walker RW, Graus F, Bataller L, Illa I, Markx S, Strauss KA, Peles E, Scherer SS, Dalmau J: Investigations of caspr2, an autoantigen of encephalitis and neuromyotonia. Ann Neurol 2011, 69:303-311.

103. Lancaster E, Lai M, Peng X, Hughes E, Constantinescu R, Raizer J, Friedman D, Skeen MB, Grisold W, Kimura A, Ohta K, lizuka T, Guzman M, Graus F, Moss SJ, Balice-Gordon R, Dalmau J: Antibodies to the GABA(B) receptor in limbic encephalitis with seizures: case series and characterisation of the antigen. Lancet Neurol 2010, 9:67-76.

104. Lancaster E, Martinez-Hernandez E, Titulaer MJ, Boulos M, Weaver S, Antoine JC, Liebers E, Kornblum C, Bien CG, Honnorat J, Wong S, Xu J, Contractor A, Balice-Gordon R, Dalmau J: Antibodies to metabotropic glutamate receptor 5 in the Ophelia syndrome. Neurology 2011, 77:1698-1701. 
105. Ances BM, Vitaliani R, Taylor RA, Liebeskind DS, Voloschin A, Houghton DJ, Galetta SL, Dichter M, Alavi A, Rosenfeld MR, Dalmau J: Treatmentresponsive limbic encephalitis identified by neuropil antibodies: MRI and PET correlates. Brain 2005, 128:1764-1777.

106. Tofaris GK, Irani SR, Cheeran BJ, Baker IW, Cader ZM, Vincent A: Immunotherapy-responsive chorea as the presenting feature of LGI1antibody encephalitis. Neurology 2012, 79:195-196.

107. Najjar S, Pearlman D, Najjar A, Ghiasian V, Zagzag D, Devinsky O: Extralimbic autoimmune encephalitis associated with glutamic acid decarboxylase antibodies: an underdiagnosed entity? Epilepsy Behav 2011, 21:306-313.

108. Titulaer MJ, McCracken L, Gabilondo I, Armangue T, Glaser C, lizuka T, Honig LS, Benseler SM, Kawachi I, Martinez-Hernandez E, Aguilar E, Gresa-Arribas N, Ryan-Florance N, Torrents A, Saiz A, Rosenfeld MR, Balice-Gordon R, Graus F, Dalmau J: Treatment and prognostic factors for long-term outcome in patients with anti-NMDA receptor encephalitis: an observational cohort study. Lancet Neurol 2013, 12:157-165.

109. Dalmau J, Gleichman AJ, Hughes EG, Rossi JE, Peng X, Lai M, Dessain SK, Rosenfeld MR, Balice-Gordon R, Lynch DR: Anti-NMDA-receptor encephalitis: case series and analysis of the effects of antibodies. Lancet Neurol 2008, 7:1091-1098.

110. Graus F, Boronat A, Xifro X, Boix M, Svigelj V, Garcia A, Palomino A, Sabater $L$, Alberch J, Saiz A: The expanding clinical profile of anti-AMPA receptor encephalitis. Neurology 2010, 74:857-859.

111. Lai M, Hughes EG, Peng X, Zhou L, Gleichman AJ, Shu H, Mata S, Kremens D, Vitaliani R, Geschwind MD, Bataller L, Kalb RG, Davis R, Graus F, Lynch DR, Balice-Gordon R, Dalmau J: AMPA receptor antibodies in limbic encephalitis alter synaptic receptor location. Ann Neurol 2009, 65:424-434.

112. Najjar S, Pearlman D, Devinsky O, Najjar A, Nadkarni S, Butler T, Zagzag D: Neuropsychiatric autoimmune encephalitis with negative VGKC-complex, NMDAR, and GAD autoantibodies: a case report and literature review, forthcoming. Cogn Behav Neurol. in press.

113. Najjar S, Pearlman D, Zagzag D, Devinsky O: Spontaneously resolving seronegative autoimmune limbic encephalitis. Cogn Behav Neurol 2011, 24:99-105.

114. Gabilondo I, Saiz A, Galan L, Gonzalez V, Jadraque R, Sabater L, Sans A, Sempere A, Vela A, Villalobos F, Viñals M, Villoslada P, Graus F: Analysis of relapses in anti-NMDAR encephalitis. Neurology 2011, 77:996-999.

115. Barry H, Hardiman O, Healy DG, Keogan M, Moroney J, Molnar PP, Cotter DR, Murphy KC: Anti-NMDA receptor encephalitis: an important differential diagnosis in psychosis. Br J Psychiatry 2011, 199:508-509.

116. Dickerson F, Stallings C, Vaughan C, Origoni A, Khushalani S, Yolken R: Antibodies to the glutamate receptor in mania. Bipolar Disord 2012, 14:547-553.

117. O'Loughlin K, Ruge P, McCauley M: Encephalitis and schizophrenia: a matter of words. Br J Psychiatry 2012, 201:74.

118. Parratt KL, Allan M, Lewis SJ, Dalmau J, Halmagyi GM, Spies JM: Acute psychiatric illness in a young woman: an unusual form of encephalitis. Med J Aust 2009, 191:284-286.

119. Suzuki Y, Kurita T, Sakurai K, Takeda Y, Koyama T: Case report of anti-NMDA receptor encephalitis suspected of schizophrenia. Seishin Shinkeigaku Zasshi 2009, 111:1479-1484.

120. Tsutsui K, Kanbayashi T, Tanaka K, Boku S, Ito W, Tokunaga J, Mori A, Hishikawa Y, Shimizu T, Nishino S: Anti-NMDA-receptor antibody detected in encephalitis, schizophrenia, and narcolepsy with psychotic features. BMC Psychiatry 2012, 12:37

121. Van Putten WK, Hachimi-Idrissi S, Jansen A, Van Gorp V, Huyghens L: Uncommon cause of psychotic behavior in a 9-year-old girl: a case report. Case Report Med 2012, 2012:358520.

122. Masdeu JC, Gonzalez-Pinto A, Matute C, Ruiz De Azua S, Palomino A, De Leon J, Berman KF, Dalmau J: Serum IgG antibodies against the NR1 subunit of the NMDA receptor not detected in schizophrenia. Am J Psychiatry 2012, 169:1120-1121.

123. Kirvan CA, Swedo SE, Kurahara D, Cunningham MW: Streptococcal mimicry and antibody-mediated cell signaling in the pathogenesis of Sydenham's chorea. Autoimmunity 2006, 39:21-29.

124. Swedo SE: Streptoccocal infection, Tourette syndrome, and OCD: is there a connection? Pandas: Horse or zebra? Neurology 2010, 74:1397-1398.

125. Morer A, Lazaro L, Sabater L, Massana J, Castro J, Graus F: Antineuronal antibodies in a group of children with obsessive-compulsive disorder and Tourette syndrome. J Psychiatr Res 2008, 42:64-68.
126. Pavone $P$, Bianchini R, Parano E, Incorpora G, Rizzo R, Mazzone L, Trifiletti RR: Anti-brain antibodies in PANDAS versus uncomplicated streptococcal infection. Pediatr Neurol 2004, 30:107-110.

127. Maina G, Albert U, Bogetto F, Borghese C, Berro AC, Mutani R, Rossi F, Vigliani MC: Anti-brain antibodies in adult patients with obsessivecompulsive disorder. J Affect Disord 2009, 116:192-200.

128. Brimberg L, Benhar I, Mascaro-Blanco A, Alvarez K, Lotan D, Winter C, Klein J, Moses AE, Somnier FE, Leckman JF, Swedo SE, Cunningham MW, Joel D: Behavioral, pharmacological, and immunological abnormalities after streptococcal exposure: a novel rat model of Sydenham chorea and related neuropsychiatric disorders. Neuropsychopharmacology 2012, 37:2076-2087.

129. Dale RC, Candler PM, Church AJ, Wait R, Pocock JM, Giovannoni G: Neuronal surface glycolytic enzymes are autoantigen targets in post-streptococcal autoimmune CNS disease. J Neuroimmunol 2006, 172:187-197.

130. Nicholson TR, Ferdinando S, Krishnaiah RB, Anhoury S, Lennox BR, MataixCols D, Cleare A, Veale DM, Drummond LM, Fineberg NA, Church AJ, Giovannoni G, Heyman I: Prevalence of anti-basal ganglia antibodies in adult obsessive-compulsive disorder: cross-sectional study. $\mathrm{Br} J$ Psychiatry 2012, 200:381-386.

131. Wu K, Hanna GL, Rosenberg DR, Arnold PD: The role of glutamate signaling in the pathogenesis and treatment of obsessive-compulsive disorder. Pharmacol Biochem Behav 2012, 100:726-735.

132. Perlmutter SJ, Leitman SF, Garvey MA, Hamburger S, Feldman E, Leonard $\mathrm{HL}$, Swedo SE: Therapeutic plasma exchange and intravenous immunoglobulin for obsessive-compulsive disorder and tic disorders in childhood. Lancet 1999, 354:1153-1158.

133. Pereira A Jr, Furlan FA: Astrocytes and human cognition: modeling information integration and modulation of neuronal activity. Prog Neurobiol 2010, 92:405-420.

134. Barres BA: The mystery and magic of glia: a perspective on their roles in health and disease. Neuron 2008, 60:430-440.

135. Verkhratsky A, Parpura V, Rodriguez JJ: Where the thoughts dwell: the physiology of neuronal-glial "diffuse neural net". Brain Res Rev 2011, 66:133-151.

136. Sofroniew MV: Molecular dissection of reactive astrogliosis and glial scar formation. Trends Neurosci 2009, 32:638-647.

137. Hamilton NB, Attwell D: Do astrocytes really exocytose neurotransmitters? Nat Rev Neurosci 2010, 11:227-238.

138. Rajkowska G: Postmortem studies in mood disorders indicate altered numbers of neurons and glial cells. Biol Psychiatry 2000, 48:766-777.

139. Coupland NJ, Ogilvie CJ, Hegadoren KM, Seres P, Hanstock CC, Allen PS: Decreased prefrontal Myo-inositol in major depressive disorder. Biol Psychiatry 2005, 57:1526-1534.

140. Miguel-Hidalgo JJ, Overholser JC, Jurjus GJ, Meltzer HY, Dieter L, Konick L, Stockmeier CA, Rajkowska G: Vascular and extravascular immunoreactivity for intercellular adhesion molecule 1 in the orbitofrontal cortex of subjects with major depression: age-dependent changes. $J$ Affect Disord 2011, 132:422-431.

141. Miguel-Hidalgo JJ, Wei JR, Andrew M, Overholser JC, Jurjus G, Stockmeie CA, Rajkowska G: Glia pathology in the prefrontal cortex in alcohol dependence with and without depressive symptoms. Biol Psychiatry 2002, 52:1121-1133.

142. Stockmeier CA, Mahajan GJ, Konick LC, Overholser JC, Jurjus GJ, Meltzer HY, Uylings HB, Friedman L, Rajkowska G: Cellular changes in the postmortem hippocampus in major depression. Biol Psychiatry 2004, 56:640-650.

143. Ongür D, Drevets WC, Price JL: Glial reduction in the subgenual prefrontal cortex in mood disorders. Proc Natl Acad Sci USA 1998, 95:13290-13295.

144. Gittins RA, Harrison PJ: A morphometric study of glia and neurons in the anterior cingulate cortex in mood disorder. J Affect Disord 2011, 133:328-332.

145. Cotter D, Mackay D, Beasley C, Kerwin R, Everall I: Reduced glial density and neuronal volume in major depressive disorder and schizophrenia in the anterior cingulate cortex [abstract]. Schizophrenia Res 2000, 41:106.

146. Si X, Miguel-Hidalgo JJ, Rajkowska G: GFAP expression is reduced in the dorsolateral prefrontal cortex in depression. In Society for Neuroscience; 2003. Neuroscience Meeting Planne: New Orleans; 2003.

147. Legutko B, Mahajan G, Stockmeier CA, Rajkowska G: White matter astrocytes are reduced in depression. In Society for Neuroscience. Neuroscience Meeting Planner: Washington, DC; 2011. 
148. Edgar N, Sibille E: A putative functional role for oligodendrocytes in mood regulation. Transl Psychiatry 2012, 2:e109.

149. Rajkowska G, Halaris A, Selemon LD: Reductions in neuronal and glial density characterize the dorsolateral prefrontal cortex in bipolar disorder. Biol Psychiatry 2001, 49:741-752.

150. Cotter D, Mackay D, Chana G, Beasley C, Landau S, Everall IP: Reduced neuronal size and glial cell density in area 9 of the dorsolateral prefrontal cortex in subjects with major depressive disorder. Cereb Cortex 2002, 12:386-394.

151. Stark AK, Uylings HB, Sanz-Arigita E, Pakkenberg B: Glial cell loss in the anterior cingulate cortex, a subregion of the prefrontal cortex, in subjects with schizophrenia. Am J Psychiatry 2004, 161:882-888.

152. Konopaske GT, Dorph-Petersen KA, Sweet RA, Pierri JN, Zhang W, Sampson $A R$, Lewis DA: Effect of chronic antipsychotic exposure on astrocyte and oligodendrocyte numbers in macaque monkeys. Biol Psychiatry 2008, 63:759-765

153. Selemon LD, Lidow MS, Goldman-Rakic PS: Increased volume and glial density in primate prefrontal cortex associated with chronic antipsychotic drug exposure. Biol Psychiatry 1999, 46:161-172.

154. Steiner J, Bernstein HG, Bielau H, Farkas N, Winter J, Dobrowolny H, Brisch R, Gos T, Mawrin C, Myint AM, Bogerts B: S100B-immunopositive glia is elevated in paranoid as compared to residual schizophrenia: a morphometric study. J Psychiatr Res 2008, 42:868-876.

155. Carter CJ: elF2B and oligodendrocyte survival: where nature and nurture meet in bipolar disorder and schizophrenia? Schizophr Bull 2007, 33:1343-1353.

156. Hayashi Y, Nihonmatsu-Kikuchi N, Hisanaga S, Yu XJ, Tatebayashi Y: Neuropathological similarities and differences between schizophrenia and bipolar disorder: a flow cytometric postmortem brain study. PLoS One 2012, 7:e33019.

157. Uranova NA, Vikhreva OV, Rachmanova VI, Orlovskaya DD: Ultrastructural alterations of myelinated fibers and oligodendrocytes in the prefrontal cortex in schizophrenia: a postmortem morphometric study. Schizophr Res Treatment 2011, 2011:325789.

158. Torres-Platas SG, Hercher C, Davoli MA, Maussion G, Labonte B, Tureck $G$, Mechawar N: Astrocytic hypertrophy in anterior cingulate white matter of depressed suicides. Neuropsychopharmacology 2011, 36:2650-2658

159. Pereira A Jr, Furlan FA: On the role of synchrony for neuron-astrocyte interactions and perceptual conscious processing. J Biol Phys 2009, 35:465-480.

160. Kettenmann H, Hanisch UK, Noda M, Verkhratsky A: Physiology of microglia. Physiol Rev 2011, 91:461-553.

161. Tremblay ME, Stevens B, Sierra A, Wake H, Bessis A, Nimmerjahn A: The role of microglia in the healthy brain. J Neurosci 2011, 31:16064-16069.

162. Kaindl AM, Degos V, Peineau S, Gouadon E, Chhor V, Loron G, Le Charpentier T, Josserand J, Ali C, Vivien D, Collingridge GL, Lombet A, Issa L, Rene F, Loeffler JP, Kavelaars A, Verney C, Mantz J, Gressens P: Activation of microglial $\mathrm{N}$-methyl-D-aspartate receptors triggers inflammation and neuronal cell death in the developing and mature brain. Ann Neurol 2012, 72:536-549.

163. Schwartz M, Shaked I, Fisher J, Mizrahi T, Schori H: Protective autoimmunity against the enemy within: fighting glutamate toxicity. Trends Neurosci 2003, 26:297-302.

164. Pacheco R, Gallart T, Lluis C, Franco R: Role of glutamate on T-cell mediated immunity. J Neuroimmunol 2007, 185:9-19.

165. Najjar S, Pearlman D, Miller DC, Devinsky O: Refractory epilepsy associated with microglial activation. Neurologist 2011, 17:249-254.

166. Schwartz M, Butovsky O, Bruck W, Hanisch UK: Microglial phenotype: is the commitment reversible? Trends Neurosci 2006, 29:68-74.

167. Wang F, Wu H, Xu S, Guo X, Yang J, Shen X: Macrophage migration inhibitory factor activates cyclooxygenase 2-prostaglandin E2 in cultured spinal microglia. Neurosci Res 2011, 71:210-218.

168. Zhang XY, Xiu MH, Song C, Chenda C, Wu GY, Haile CN, Kosten TA, Kosten TR: Increased serum S100B in never-medicated and medicated schizophrenic patients. J Psychiatr Res 2010, 44:1236-1240

169. Kawasaki Y, Zhang L, Cheng JK, Ji RR: Cytokine mechanisms of central sensitization: distinct and overlapping role of interleukin-1 beta, interleukin-6, and tumor necrosis factor-alpha in regulating synaptic and neuronal activity in the superficial spinal cord. J Neurosci 2008, 28:5189-5194
170. Müller N, Schwarz MJ: The immunological basis of glutamatergic disturbance in schizophrenia: towards an integrated view. J Neural Transm Suppl 2007, 72:269-280

171. Hestad KA, Tonseth S, Stoen CD, Ueland T, Aukrust P: Raised plasma levels of tumor necrosis factor alpha in patients with depression: normalization during electroconvulsive therapy. J ECT 2003, 19:183-188.

172. Kubera M, Kenis G, Bosmans E, Zieba A, Dudek D, Nowak G, Maes M: Plasma levels of interleukin-6, interleukin-10, and interleukin-1 receptor antagonist in depression: comparison between the acute state and after remission. Pol J Pharmacol 2000, 52:237-241.

173. Miller BJ, Buckley P, Seabolt W, Mellor A, Kirkpatrick B: Meta-analysis of cytokine alterations in schizophrenia: clinical status and antipsychotic effects. Biol Psychiatry 2011, 70:663-671.

174. Potvin S, Stip E, Sepehry AA, Gendron A, Bah R, Kouassi E: Inflammatory cytokine alterations in schizophrenia: a systematic quantitative review. Biol Psychiatry 2008, 63:801-808.

175. Reale M, Patruno A, De Lutiis MA, Pesce M, Felaco M, Di Giannantonio M, Di Nicola M, Grilli A: Dysregulation of chemo-cytokine production in schizophrenic patients versus healthy controls. BMC Neurosci 2011, 12:13.

176. Fluitman SB, Denys DA, Heijnen CJ, Westenberg HG: Disgust affects TNFalpha, IL-6 and noradrenalin levels in patients with obsessive-compulsive disorder. Psychoneuroendocrinology 2010, 35:906-911.

177. Konuk N, Tekin IO, Ozturk U, Atik L, Atasoy N, Bektas S, Erdogan A: Plasma levels of tumor necrosis factor-alpha and interleukin-6 in obsessive compulsive disorder. Mediators Inflamm 2007, 2007:65704.

178. Monteleone P, Catapano F, Fabrazzo M, Tortorella A, Maj M: Decreased blood levels of tumor necrosis factor-alpha in patients with obsessivecompulsive disorder. Neuropsychobiology 1998, 37:182-185.

179. Marazziti D, Presta S, Pfanner C, Gemignani A, Rossi A, Sbrana S, Rocchi V, Ambrogi F, Cassano GB: Immunological alterations in adult obsessivecompulsive disorder. Biol Psychiatry 1999, 46:810-814.

180. Zai G, Arnold PD, Burroughs E, Richter MA, Kennedy JL: Tumor necrosis factor-alpha gene is not associated with obsessive-compulsive disorder. Psychiatr Genet 2006, 16:43.

181. Rodríguez AD, González PA, García MJ, de la Rosa A, Vargas M, Marrero F: Circadian variations in proinflammatory cytokine concentrations in acute myocardial infarction. Rev Esp Cardiol 2003, 56:555-560.

182. Oliver JC, Bland LA, Oettinger CW, Arduino MJ, McAllister SK, Aguero SM Favero MS: Cytokine kinetics in an in vitro whole blood model following an endotoxin challenge. Lymphokine Cytokine Res 1993, 12:115-120.

183. Le T, Leung L, Carroll WL, Schibler KR: Regulation of interleukin-10 gene expression: possible mechanisms accounting for its upregulation and for maturational differences in its expression by blood mononuclear cells. Blood 1997, 89:4112-4119.

184. Lee MC, Ting KK, Adams S, Brew BJ, Chung R, Guillemin GJ: Characterisation of the expression of NMDA receptors in human astrocytes. PloS One 2010, 5:e14123.

185. Myint AM, Kim YK, Verkerk R, Scharpe S, Steinbusch H, Leonard B: Kynurenine pathway in major depression: evidence of impaired neuroprotection. J Affect Disord 2007, 98:143-151.

186. Sanacora G, Treccani G, Popoli M: Towards a glutamate hypothesis of depression: an emerging frontier of neuropsychopharmacology for mood disorders. Neuropharmacology 2012, 62:63-77.

187. Saleh A, Schroeter M, Jonkmanns C, Hartung HP, Modder U, Jander S: In vivo MRI of brain inflammation in human ischaemic stroke. Brain 2004 , 127:1670-1677.

188. Tilleux S, Hermans E: Neuroinflammation and regulation of glial glutamate uptake in neurological disorders. J Neurosci Res 2007, 85:2059-2070.

189. Helms HC, Madelung R, Waagepetersen HS, Nielsen CU, Brodin B: In vitro evidence for the brain glutamate efflux hypothesis: brain endothelial cells cocultured with astrocytes display a polarized brain-to-blood transport of glutamate. 2012, 60:882-893.

190. Leonard BE: The concept of depression as a dysfunction of the immune system. Curr Immunol Rev 2010, 6:205-212.

191. Labrie V, Wong AH, Roder JC: Contributions of the D-serine pathway to schizophrenia. Neuropharmacology 2012, 62:1484-1503.

192. Gras G, Samah B, Hubert A, Leone C, Porcheray F, Rimaniol AC: EAAT expression by macrophages and microglia: still more questions than answers. Amino Acids 2012, 42:221-229.

193. Livingstone PD, Dickinson JA, Srinivasan J, Kew JN, Wonnacott S: Glutamate-dopamine crosstalk in the rat prefrontal cortex is modulated 
by Alpha7 nicotinic receptors and potentiated by PNU-120596. $\mathrm{J} \mathrm{Mol}$ Neurosci 2010, 40:172-176.

194. Kondziella D, Brenner E, Eyjolfsson EM, Sonnewald U: How do glialneuronal interactions fit into current neurotransmitter hypotheses of schizophrenia? Neurochem Int 2007, 50:291-301.

195. Wu HQ, Pereira EF, Bruno JP, Pellicciari R, Albuquerque EX, Schwarcz R: The astrocyte-derived alpha7 nicotinic receptor antagonist kynurenic acid controls extracellular glutamate levels in the prefrontal cortex. $\mathrm{J} \mathrm{Mol}$ Neurosci 2010, 40:204-210.

196. Steiner J, Bogerts B, Schroeter ML, Bernstein HG: S100B protein in neurodegenerative disorders. Clin Chem Lab Med 2011, 49:409-424

197. Steiner J, Marquardt N, Pauls I, Schiltz K, Rahmoune H, Bahn S, Bogerts B, Schmidt RE, Jacobs R: Human CD8(+) T cells and NK cells express and secrete S100B upon stimulation. Brain Behav Immun 2011, 25:1233-1241.

198. Shanmugam N, Kim YS, Lanting L, Natarajan R: Regulation of cyclooxygenase-2 expression in monocytes by ligation of the receptor for advanced glycation end products. J Biol Chem 2003, 278:34834-34844.

199. Rothermundt M, Ohrmann P, Abel S, Siegmund A, Pedersen A, Ponath G, Suslow T, Peters M, Kaestner F, Heindel W, Arolt V, Pfleiderer B: Glial cell activation in a subgroup of patients with schizophrenia indicated by increased S100B serum concentrations and elevated myo-inositol. Prog Neuropsychopharmacol Biol Psychiatry 2007, 31:361-364.

200. Falcone T, Fazio V, Lee C, Simon B, Franco K, Marchi N, Janigro D: Serum S100B: a potential biomarker for suicidality in adolescents? PLoS One 2010, 5:e11089.

201. Schroeter ML, Abdul-Khaliq H, Krebs M, Diefenbacher A, Blasig IE: Serum markers support disease-specific glial pathology in major depression. J Affect Disord 2008, 111:271-280.

202. Rothermundt M, Ahn JN, Jorgens S: S100B in schizophrenia: an update. Gen Physiol Biophys 2009, 28 Spec No Focus:F76-F81

203. Schroeter ML, Abdul-Khaliq H, Krebs M, Diefenbacher A, Blasig IE: Neuronspecific enolase is unaltered whereas S100B is elevated in serum of patients with schizophrenia-original research and meta-analysis. Psychiatry Res 2009, 167:66-72.

204. Rothermundt M, Missler U, Arolt V, Peters M, Leadbeater J, Wiesmann M, Rudolf S, Wandinger KP, Kirchner H: Increased S100B blood levels in unmedicated and treated schizophrenic patients are correlated with negative symptomatology. Mol Psychiatry 2001, 6:445-449.

205. Suchankova P, Klang J, Cavanna C, Holm G, Nilsson S, Jonsson EG, Ekman A: Is the Gly82Ser polymorphism in the RAGE gene relevant to schizophrenia and the personality trait psychoticism? I Psychiatry Neurosci 2012, 37:122-128.

206. Scapagnini G, Davinelli S, Drago F, De Lorenzo A, Oriani G: Antioxidants as antidepressants: fact or fiction? CNS Drugs 2012, 26:477-490

207. Ng F, Berk M, Dean O, Bush Al: Oxidative stress in psychiatric disorders: evidence base and therapeutic implications. Int I Neuropsychopharmacol 2008, 11:851-876.

208. Salim S, Chugh G, Asghar M: Inflammation in anxiety. Adv Protein Chem Struct Biol 2012, 88:1-25.

209. Anderson G, Berk M, Dodd S, Bechter K, Altamura AC, Dell'osso B, Kanba S, Monji A, Fatemi SH, Buckley P, Debnath M, Das UN, Meyer U, Müller N, Kanchanatawan B, Maes M: Immuno-inflammatory, oxidative and nitrosative stress, and neuroprogressive pathways in the etiology, course and treatment of schizophrenia. Prog Neuropsychopharmacol Biol Psychiatry 2013, 42:1-42.

210. Coughlin JM, Ishizuka K, Kano SI, Edwards JA, Seifuddin FT, Shimano MA, Daley EL, et al: Marked reduction of soluble superoxide dismutase-1 (SOD1) in cerebrospinal fluid of patients with recent-onset schizophrenia. Mol Psychiatry 2012, 18:10-11.

211. Bombaci M, Grifantini R, Mora M, Reguzzi V, Petracca R, Meoni E, Balloni S, Zingaretti C, Falugi F, Manetti AG, Margarit I, Musser JM, Cardona F, Orefici $G$, Grandi G, Bensi G: Protein array profiling of tic patient sera reveals a broad range and enhanced immune response against Group A Streptococcus antigens. PLoS One 2009, 4:e6332.

212. Valerio A, Cardile A, Cozzi V, Bracale R, Tedesco L, Pisconti A, Palomba L, Cantoni O, Clementi E, Moncada S, Carruba MO, Nisoli E: TNF-alpha downregulates eNOS expression and mitochondrial biogenesis in fat and muscle of obese rodents. J Clin Invest 2006, 116:2791-2798.

213. Ott M, Gogvadze V, Orrenius S, Zhivotovsky B: Mitochondria, oxidative stress and cell death. Apoptosis 2007, 12:913-922.

214. Shalev H, Serlin Y, Friedman A: Breaching the blood-brain barrier as a gate to psychiatric disorder. Cardiovasc Psychiatry Neurol 2009, 2009:278531.
215. Abbott NJ, Ronnback L, Hansson E: Astrocyte-endothelial interactions at the blood-brain barrier. Nat Rev Neurosci 2006, 7:41-53.

216. Bechter K, Reiber H, Herzog S, Fuchs D, Tumani H, Maxeiner HG: Cerebrospinal fluid analysis in affective and schizophrenic spectrum disorders: identification of subgroups with immune responses and blood-CSF barrier dysfunction. J Psychiatr Res 2010, 44:321-330.

217. Harris LW, Wayland M, Lan M, Ryan M, Giger T, Lockstone H, Wuethrich I, Mimmack M, Wang L, Kotter M, Craddock R, Bahn S: The cerebral microvasculature in schizophrenia: a laser capture microdissection study. PLoS One 2008, 3:e3964.

218. Lin JJ, Mula M, Hermann BP: Uncovering the neurobehavioural comorbidities of epilepsy over the lifespan. Lancet 2012, 380:1180-1192.

219. Isingrini E, Belzung C, Freslon JL, Machet MC, Camus V: Fluoxetine effect on aortic nitric oxide-dependent vasorelaxation in the unpredictable chronic mild stress model of depression in mice. Psychosom Med 2012, 74:63-72.

220. Zhang XY, Zhou DF, Cao LY, Zhang PY, Wu GY, Shen YC: The effect of risperidone treatment on superoxide dismutase in schizophrenia. J Clin Psychopharmacol 2003, 23:128-131.

221. Lavoie KL, Pelletier R, Arsenault A, Dupuis J, Bacon SL: Association between clinical depression and endothelial function measured by forearm hyperemic reactivity. Psychosom Med 2010, 72:20-26.

222. Chrapko W, Jurasz P, Radomski MW, Archer SL, Newman SC, Baker G, Lara N, Le Melledo JM: Alteration of decreased plasma NO metabolites and platelet NO synthase activity by paroxetine in depressed patients. Neuropsychopharmacology 2006, 31:1286-1293.

223. Chrapko WE, Jurasz P, Radomski MW, Lara N, Archer SL, Le Melledo JM: Decreased platelet nitric oxide synthase activity and plasma nitric oxide metabolites in major depressive disorder. Biol Psychiatry 2004, 56:129-134.

224. Stuehr DJ, Santolini J, Wang ZQ, Wei CC, Adak S: Update on mechanism and catalytic regulation in the NO synthases. J Biol Chem 2004, 279:36167-36170.

225. Chen W, Druhan $\sqcup$, Chen CA, Hemann C, Chen YR, Berka V, Tsai AL, Zweier $J \mathrm{~L}:$ Peroxynitrite induces destruction of the tetrahydrobiopterin and heme in endothelial nitric oxide synthase: transition from reversible to irreversible enzyme inhibition. Biochemistry 2010, 49:3129-3137.

226. Chen CA, Wang TY, Varadharaj S, Reyes LA, Hemann C, Talukder MA, Chen YR, Druhan $\sqcup$, Zweier JL: S-glutathionylation uncouples eNOS and regulates its cellular and vascular function. Nature 2010, 468:1115-1118.

227. Szabo C, Ischiropoulos H, Radi R: Peroxynitrite: biochemistry, pathophysiology and development of therapeutics. Nat Rev Drug Discov 2007, 6:662-680.

228. Papakostas Gl, Shelton RC, Zajecka JM, Etemad B, Rickels K, Clain A, Baer L, Dalton ED, Sacco GR, Schoenfeld D, Pencina M, Meisner A, Bottiglieri T, Nelson E, Mischoulon D, Alpert JE, Barbee JG, Zisook S, Fava M: Lmethylfolate as adjunctive therapy for SSRI-resistant major depression: results of two randomized, double-blind, parallel-sequential trials. Am J Psychiatry 2012, 169:1267-1274.

229. Antoniades C, Shirodaria C, Warrick N, Cai S, de Bono J, Lee J, Leeson P, Neubauer S, Ratnatunga C, Pillai R, Refsum H, Channon KM: 5methyltetrahydrofolate rapidly improves endothelial function and decreases superoxide production in human vessels: effects on vascular tetrahydrobiopterin availability and endothelial nitric oxide synthase coupling. Circulation 2006, 114:1193-1201.

230. Masano T, Kawashima S, Toh R, Satomi-Kobayashi S, Shinohara M, Takaya T, Sasaki N, Takeda M, Tawa H, Yamashita T, Yokoyama M, Hirata K: Beneficial effects of exogenous tetrahydrobiopterin on left ventricular remodeling after myocardial infarction in rats: the possible role of oxidative stress caused by uncoupled endothelial nitric oxide synthase. Circ J 2008, 72:1512-1519.

231. Alp NJ, Channon KM: Regulation of endothelial nitric oxide synthase by tetrahydrobiopterin in vascular disease. Arterioscler Thromb Vasc Biol 2004, 24:413-420.

232. Szymanski S, Ashtari M, Zito J, Degreef G, Bogerts B, Lieberman J: Gadolinium-DTPA enhanced gradient echo magnetic resonance scans in first episode of psychosis and chronic schizophrenic patients. Psychiatry Res 1991, 40:203-207.

233. Butler T, Weisholtz D, Isenberg N, Harding E, Epstein J, Stern E, Silbersweig D: Neuroimaging of frontal-limbic dysfunction in schizophrenia and epilepsy-related psychosis: toward a convergent neurobiology. Epilepsy Behav 2012, 23:113-122. 
234. Butler T, Maoz A, Vallabhajosula S, Moeller J, Ichise M, Paresh K, Pervez F, Friedman D, Goldsmith S, Najjar S, Osborne J, Solnes L, Wang X, French J, Thesen T, Devinsky O, Kuzniecky R, Stern E, Silbersweig D: Imaging inflammation in a patient with epilepsy associated with antibodies to glutamic acid decarboxylase [abstract]. In Am Epilepsy Society Abstracts, Volume 2. Baltimore: American Epilepsy Society; 2011:191.

235. van Berckel BN, Bossong MG, Boellaard R, Kloet R, Schuitemaker A, Caspers E, Luurtsema G, Windhorst AD, Cahn W, Lammertsma AA, Kahn RS: Microglia activation in recent-onset schizophrenia: a quantitative (R)[11C]PK11195 positron emission tomography study. Biol Psychiatry 2008, 64:820-822

236. Doorduin J, de Vries EF, Willemsen AT, de Groot JC, Dierckx RA, Klein HC: Neuroinflammation in schizophrenia-related psychosis: a PET study. J Nucl Med 2009, 50:1801-1807.

237. Takano A, Arakawa R, Ito H, Tateno A, Takahashi H, Matsumoto R, Okubo Y, Suhara T: Peripheral benzodiazepine receptors in patients with chronic schizophrenia: a PET study with [11C]DAA1106. Int J Neuropsychopharmacol 2010, 13:943-950.

238. Müller N, Schwarz MJ, Dehning S, Douhe A, Cerovecki A, Goldstein-Muller B, Spellmann I, Hetzel G, Maino K, Kleindienst N, Möller HJ, Arolt V, Riedel M: The cyclooxygenase-2 inhibitor celecoxib has therapeutic effects in major depression: results of a double-blind, randomized, placebo controlled, add-on pilot study to reboxetine. Mol Psychiatry 2006, 11:680-684.

239. Akhondzadeh S, Jafari S, Raisi F, Nasehi AA, Ghoreishi A, Salehi B, MohebbiRasa S, Raznahan M, Kamalipour A: Clinical trial of adjunctive celecoxib treatment in patients with major depression: a double blind and placebo controlled trial. Depress Anxiety 2009, 26:607-611.

240. Mendlewicz J, Kriwin P, Oswald P, Souery D, Alboni S, Brunello N: Shortened onset of action of antidepressants in major depression using acetylsalicylic acid augmentation: a pilot open-label study. Int Clin Psychopharmacol 2006, 21:227-231.

241. Uher R, Carver S, Power RA, Mors O, Maier W, Rietschel M, Hauser J, Dernovsek MZ, Henigsberg N, Souery D, Placentino A, Farmer A, McGuffin P: Non-steroidal anti-inflammatory drugs and efficacy of antidepressants in major depressive disorder. Psychol Med 2012, 42:2027-2035.

242. Müller N, Riedel M, Scheppach C, Brandstatter B, Sokullu S, Krampe K, Ulmschneider M, Engel RR, Moller HJ, Schwarz MJ: Beneficial antipsychotic effects of celecoxib add-on therapy compared to risperidone alone in schizophrenia. Am J Psychiatry 2002, 159:1029-1034.

243. Müller N, Riedel M, Schwarz MJ, Engel RR: Clinical effects of COX-2 inhibitors on cognition in schizophrenia. Eur Arch Psychiatry Clin Neurosci 2005, 255:149-151.

244. Müller N, Krause D, Dehning S, Musil R, Schennach-Wolff R, Obermeier M, Moller HJ, Klauss V, Schwarz MJ, Riedel M: Celecoxib treatment in an early stage of schizophrenia: results of a randomized, double-blind, placebocontrolled trial of celecoxib augmentation of amisulpride treatment. Schizophr Res 2010, 121:118-124.

245. Sayyah M, Boostani H, Pakseresht S, Malayeri A: A preliminary randomized double-blind clinical trial on the efficacy of celecoxib as an adjunct in the treatment of obsessive-compulsive disorder. Psychiatry Res 2011, 189:403-406.

246. Sublette ME, Ellis SP, Geant AL, Mann JJ: Meta-analysis of the effects of eicosapentaenoic acid (EPA) in clinical trials in depression. J Clin Psychiatry 2011, 72:1577-1584.

247. Bloch MH, Hannestad J: Omega-3 fatty acids for the treatment of depression: systematic review and meta-analysis. Mol Psychiatry 2012, 17:1272-1282

248. Keller WR, Kum LM, Wehring HJ, Koola MM, Buchanan RW, Kelly DL: A review of anti-inflammatory agents for symptoms of schizophrenia. J Psychopharmacol.

249. Warner-Schmidt JL, Vanover KE, Chen EY, Marshall JJ, Greengard P: Antidepressant effects of selective serotonin reuptake inhibitors (SSRIs) are attenuated by antiinflammatory drugs in mice and humans. Proc Natl Acad Sci USA 2011, 108:9262-9267.

250. Gallagher PJ, Castro V, Fava M, Weilburg JB, Murphy SN, Gainer VS, Churchill SE, Kohane IS, losifescu DV, Smoller JW, Perlis RH: Antidepressant response in patients with major depression exposed to NSAIDs: a pharmacovigilance study. Am J Psychiatry 2012, 169:1065-1072.

251. Shelton RC: Does concomitant use of NSAIDs reduce the effectiveness of antidepressants? Am J Psychiatry 2012, 169:1012-1015.
252. Martinez-Gras I, Perez-Nievas BG, Garcia-Bueno B, Madrigal JL, AndresEsteban E, Rodriguez-Jimenez R, Hoenicka J, Palomo T, Rubio G, Leza JC: The anti-inflammatory prostaglandin $15 \mathrm{~d}-\mathrm{PGJ} 2$ and its nuclear receptor PPARgamma are decreased in schizophrenia. Schizophr Res 2011, 128:15-22.

253. Garcia-Bueno B, Perez-Nievas BG, Leza JC: Is there a role for the nuclear receptor PPARgamma in neuropsychiatric diseases? Int J Neuropsychopharmacol 2010, 13:1411-1429.

254. Meyer U: Anti-inflammatory signaling in schizophrenia. Brain Behav Immun 2011, 25:1507-1518.

255. Ramer R, Heinemann K, Merkord J, Rohde H, Salamon A, Linnebacher M, Hinz B: COX-2 and PPAR-gamma confer cannabidiol-induced apoptosis of human lung cancer cells. Mol Cancer Ther 2013, 12:69-82.

256. Henry CJ, Huang Y, Wynne A, Hanke M, Himler J, Bailey MT, Sheridan JF, Godbout JP: Minocycline attenuates lipopolysaccharide (LPS)-induced neuroinflammation, sickness behavior, and anhedonia. J Neuroinflammation 2008, 5:15.

257. Sarris J, Mischoulon D, Schweitzer I: Omega-3 for bipolar disorder: metaanalyses of use in mania and bipolar depression. J Clin Psychiatry 2012, 73:81-86.

258. Amminger GP, Schafer MR, Papageorgiou K, Klier CM, Cotton SM, Harrigan SM, Mackinnon A, McGorry PD, Berger GE: Long-chain omega-3 fatty acids for indicated prevention of psychotic disorders: a randomized, placebocontrolled trial. Arch Gen Psychiatry 2010, 67:146-154.

259. Fusar-Poli P, Berger G: Eicosapentaenoic acid interventions in schizophrenia: meta-analysis of randomized, placebo-controlled studies. J Clin Psychopharmacol 2012, 32:179-185.

260. Zorumski CF, Paul SM, Izumi Y, Covey DF, Mennerick S: Neurosteroids, stress and depression: Potential therapeutic opportunities. Neurosci Biobehav Rev 2013, 37:109-122.

261. Uhde TW, Singareddy R: Biological Research in Anxiety Disorders. In Psychiatry as a Neuroscience. Edited by Juan Jose L-I, Wolfgang G, Mario M, Norman S. Chichester: John Wiley \& Sons, Ltd; 2002:237-286.

262. Gibson SA, Korado Z, Shelton RC: Oxidative stress and glutathione response in tissue cultures from persons with major depression. J Psychiatr Res 2012, 46:1326-1332.

263. Nery FG, Monkul ES, Hatch JP, Fonseca M, Zunta-Soares GB, Frey BN, Bowden CL, Soares JC: Celecoxib as an adjunct in the treatment of depressive or mixed episodes of bipolar disorder: a double-blind, randomized, placebo-controlled study. 2008, 23:87-94.

264. Levine J, Cholestoy A, Zimmerman J: Possible antidepressant effect of minocycline. 1996, 153:582.

265. Levkovitz Y, Mendlovich S, Riwkes S, Braw Y, Levkovitch-Verbin H, Gal G, Fennig S, Treves I, Kron S: A double-blind, randomized study of minocycline for the treatment of negative and cognitive symptoms in early-phase schizohprenia. J Clin Psychiatry 2010, 71:138-149.

266. Miyaoka T, Yasukawa R, Yasuda H, Hayashida M, Inagaki T, Horiguchi J: Possible antipsychotic effect of minocycline in patients with schizophrenia. Prog Neuropsychopharmacol Biol Psychiatry 2007, 31:304-307.

267. Miyaoka J, Yasukawa R, Yasuda H, Hayashida M, Inagaki T, Horiguchi J: Minocycline as adjunctive therapy for schizophrenia: an open-label study. 2008, 31:287-292.

268. Rodriguez Cl, Bender J Jr, Marcus SM, Snape M, Rynn M, Simpson HB: Minocycline augmentation of pharmacotherapy in obsessive-compulsive disorder: an open-label trial. 2010, 71:1247-1249.

\section{doi:10.1186/1742-2094-10-43}

Cite this article as: Najjar et al:: Neuroinflammation and psychiatric illness. Journal of Neuroinflammation 2013 10:43. 